\title{
Characterization of aerosol photooxidation flow reactors: heterogeneous oxidation, secondary organic aerosol formation and cloud condensation nuclei activity measurements
}

\author{
A. T. Lambe ${ }^{1,2}$, A. T. Ahern ${ }^{1,2}$, L. R. Williams ${ }^{2}$, J. G. Slowik ${ }^{3}$, J. P. S. Wong ${ }^{3}$, J. P. D. Abbatt ${ }^{3}$, W. H. Brune ${ }^{4}$, \\ N. L. Ng $^{2}$, J. P. Wright ${ }^{1}$, D. R. Croasdale ${ }^{1}$, D. R. Worsnop ${ }^{2}$, P. Davidovits ${ }^{1}$, and T. B. Onasch ${ }^{1,2}$ \\ ${ }^{1}$ Chemistry Department, Boston College, Chestnut Hill, MA, USA \\ ${ }^{2}$ Aerodyne Research Inc., Billerica, MA, USA \\ ${ }^{3}$ Department of Chemistry, University of Toronto, Toronto, ON, Canada \\ ${ }^{4}$ Department of Meteorology and Atmospheric Sciences, The Pennsylvania State University, State College, PA, USA
}

Received: 27 September 2010 - Published in Atmos. Meas. Tech. Discuss.: 18 November 2010

Revised: 11 February 2011 - Accepted: 26 February 2011 - Published: 4 March 2011

\begin{abstract}
Motivated by the need to develop instrumental techniques for characterizing organic aerosol aging, we report on the performance of the Toronto Photo-Oxidation Tube (TPOT) and Potential Aerosol Mass (PAM) flow tube reactors under a variety of experimental conditions. The PAM system was designed with lower surface-area-tovolume (SA/V) ratio to minimize wall effects; the TPOT reactor was designed to study heterogeneous aerosol chemistry where wall loss can be independently measured. The following studies were performed: (1) transmission efficiency measurements for $\mathrm{CO}_{2}, \mathrm{SO}_{2}$, and bis(2-ethylhexyl) sebacate (BES) particles, (2) $\mathrm{H}_{2} \mathrm{SO}_{4}$ yield measurements from the oxidation of $\mathrm{SO}_{2}$, (3) residence time distribution (RTD) measurements for $\mathrm{CO}_{2}, \mathrm{SO}_{2}$, and BES particles, (4) aerosol mass spectra, $\mathrm{O} / \mathrm{C}$ and $\mathrm{H} / \mathrm{C}$ ratios, and cloud condensation nuclei $(\mathrm{CCN})$ activity measurements of BES particles exposed to $\mathrm{OH}$ radicals, and (5) aerosol mass spectra, $\mathrm{O} / \mathrm{C}$ and $\mathrm{H} / \mathrm{C}$ ratios, CCN activity, and yield measurements of secondary organic aerosol (SOA) generated from gas-phase $\mathrm{OH}$ oxidation of $m$-xylene and $\alpha$-pinene. $\mathrm{OH}$ exposures ranged from $(2.0 \pm 1.0) \times 10^{10}$ to $(1.8 \pm 0.3) \times 10^{12} \mathrm{molec} \mathrm{cm}^{-3} \mathrm{~s}$. Where applicable, data from the flow tube reactors are compared with published results from the Caltech smog chamber. The TPOT yielded narrower RTDs. However, its transmission efficiency for $\mathrm{SO}_{2}$ was lower than that for the PAM. Transmission efficiency for BES and $\mathrm{H}_{2} \mathrm{SO}_{4}$ particles was size-dependent and was similar for the two flow
\end{abstract}

Correspondence to: T. B. Onasch (onasch@aerodyne.com) tube designs. Oxidized BES particles had similar $\mathrm{O} / \mathrm{C}$ and $\mathrm{H} / \mathrm{C}$ ratios and $\mathrm{CCN}$ activity at $\mathrm{OH}$ exposures greater than $10^{11}$ molec $\mathrm{cm}^{-3} \mathrm{~s}$, but different $\mathrm{CCN}$ activity at lower $\mathrm{OH}$ exposures. The $\mathrm{O} / \mathrm{C}$ ratio, $\mathrm{H} / \mathrm{C}$ ratio, and yield of $m$-xylene and $\alpha$-pinene SOA was strongly affected by reactor design and operating conditions, with wall interactions seemingly having the strongest influence on SOA yield. At comparable $\mathrm{OH}$ exposures, flow tube SOA was more oxidized than smog chamber SOA, possibly because of faster gas-phase oxidation relative to particle nucleation. SOA yields were lower in the TPOT than in the PAM, but CCN activity of flow-tubegenerated SOA particles was similar. For comparable $\mathrm{OH}$ exposures, $\alpha$-pinene SOA yields were similar in the PAM and Caltech chambers, but $m$-xylene SOA yields were much lower in the PAM compared to the Caltech chamber.

\section{Introduction}

For decades, smog chamber reactors have been used to simulate physical and chemical processes in the atmosphere (Turpin et al., 2000; Rudich et al., 2007; Kroll and Seinfeld, 2008). Such chambers range in size from $0.01 \mathrm{~m}^{3}$ to $250 \mathrm{~m}^{3}$ (Lonneman et al., 1981; Mentel et al., 1996), providing aerosol residence times of hours to days. While flow tube reactors have been used to study the chemistry of inorganic particles since the 1950s (Robbins and Cadle, 1958; Hanson and Lovejoy, 1995), their application to the study of organic surfaces (Cooper and Abbatt, 1996; de Gouw and Lovejoy, 1998; Bertram et al., 2001) and organic particles (Morris et al., 2002; Katrib et al., 2005; Hearn and Smith, 2006; George

Published by Copernicus Publications on behalf of the European Geosciences Union. 
et al., 2007; McNeill et al., 2008; Smith et al., 2009) is relatively recent.

Flow tube reactors, with volumes typically in the range of $0.001-0.01 \mathrm{~m}^{3}$, provide aerosol residence times of seconds to minutes. Despite shorter residence times, much higher oxidant concentrations are attainable, which facilitate higher exposure times equivalent to 1-2 weeks of atmospheric oxidation. Further, experiments that may take hours in a smog chamber can be performed in minutes in a flow tube, under conditions that can be better controlled with respect to oxidant concentration, contamination (Lonneman et al., 1981; Joshi et al., 1982) and wall interactions (McMurry and Rader, 1985; McMurry and Grosjean, 1985; Pierce et al., 2008). On the other hand, smog chambers with lower oxidant concentrations and longer residence times may more closely simulate atmospheric oxidation. All laboratory reactors are imperfect simulations of the atmosphere because they have walls that cause particle loss and can influence the chemistry of semivolatile organics and, thus, particle growth and composition (Matsunaga and Ziemann, 2010). Therefore, utilizing flow tubes and smog chamber reactors with different designs can complement each other, making it possible to extend studies over a range of parameters unattainable by either method individually, and ultimately lead towards a better understanding of atmospheric aerosol processes. The results of laboratory aerosol experiments are used as inputs to climate models. Therefore, the evaluation of experimental uncertainties associated with measurements is needed for reliable application. The characterization of different reactor designs is important to establish the reliability of the experimental techniques.

In this paper, we compare two flow tube reactors of different designs. One is a glass flow tube of conventional dimensions ( $34 \mathrm{~cm}$ length $\times 7.3 \mathrm{~cm}$ diameter) developed at the University of Toronto for controlled heterogeneous oxidation studies of particles (George et al., 2007). The other flow tube developed at the Pennsylvania State University has a significantly larger volume $(46 \mathrm{~cm}$ length $\times 22 \mathrm{~cm}$ diameter), providing a smaller surface-to-volume $(\mathrm{SA} / \mathrm{V}) \mathrm{ra}$ tio (Kang et al., 2007). The two flow tubes are designated as the Toronto Photo-Oxidation Tube (TPOT) and Potential Aerosol Mass (PAM) reactors, respectively. An important distinction between the two flow tubes is that attempts were made to minimize wall interactions in the PAM (e.g. large radial/axial ratio and flow is subsampled from the center of the reactor while flow near the walls is dumped), whereas no such attempts were made with the TPOT. The TPOT was designed to generate high $\mathrm{OH}$ concentrations for heterogeneous oxidation experiments. The PAM was designed for the study of gas-to-particle formation processes, and was adopted for aerosol kinetic studies by the Boston College - Aerodyne Research research group. The speed of flow through both flow tubes was slow: $0.35 \mathrm{~cm} \mathrm{~s}^{-1}$ in the TPOT and $0.37 \mathrm{~cm} \mathrm{~s}^{-1}$ in the PAM. The SA/V ratio is significantly smaller for the $\operatorname{PAM}\left(0.23 \mathrm{~cm}^{-1}\right)$ than for the TPOT $\left(2.8 \mathrm{~cm}^{-1}\right)$; however, the larger volume of the PAM may facilitate more convection or dead volume. Results are compared to smog chamber data where applicable.

The following studies were performed: (1) transmission efficiency measurements for $\mathrm{CO}_{2}, \mathrm{SO}_{2}$, and bis(2ethylhexyl) sebacate (BES) particles, (2) $\mathrm{H}_{2} \mathrm{SO}_{4}$ yield measurements from the oxidation of $\mathrm{SO}_{2},(3)$ residence time distribution (RTD) measurements for $\mathrm{CO}_{2}, \mathrm{SO}_{2}$, and BES particles, (4) aerosol mass spectrometer (AMS) and cloud condensation nuclei $(\mathrm{CCN})$ activity measurements of BES particles exposed to $\mathrm{OH}$ radicals, and (5) AMS, CCN activity, and yield measurements of secondary organic aerosol (SOA) generated from gas-phase $\mathrm{OH}$ oxidation of $m$-xylene and $\alpha$ pinene. The purpose of the study is to assess the effects of flow tube design differences on reactor performance and ultimately on the atmospheric relevance of laboratory-based SOA measurements.

\section{Experimental}

A schematic of the experimental setup is shown in Fig. 1. Gas/particle sources and monitoring instruments were shared by the TPOT and PAM, with 3-way valves placed upstream and downstream to switch flows and monitoring instruments between reactors. Input lines 1 and 2 provide gases for the production of $\mathrm{OH}$ radicals. Line 3 supplies gas-phase $\alpha$ pinene or $m$-xylene for the production of $\mathrm{SOA}$, or $\mathrm{SO}_{2}$ for the production of $\mathrm{H}_{2} \mathrm{SO}_{4}$. Line 4 provides monodisperse BES particles. BES and $\mathrm{H}_{2} \mathrm{SO}_{4}$ were used as proxies for primary and secondary aerosols in specific characterization studies. Smog chamber data used in the intercomparison were obtained in the dual $28-\mathrm{m}^{3}$ Caltech chambers; experimental details are described in $\mathrm{Ng}$ et al. $(2007 \mathrm{a}, \mathrm{b})$.

\subsection{OH radical generation}

$\mathrm{O}_{3}$ was produced from external irradiation of $\mathrm{O}_{2}$ with a mercury lamp $(\lambda=185 \mathrm{~nm})$ and was measured with an $\mathrm{O}_{3}$ monitor (2B Technologies). Excited oxygen $\left[\mathrm{O}\left({ }^{1} \mathrm{D}\right)\right]$ atoms are produced from UV photolysis of $O_{3}(\lambda=254 \mathrm{~nm})$ inside the flow tubes at a relative humidity of $25-30 \%$. The radical $\mathrm{O}\left({ }^{1} \mathrm{D}\right)$ then reacts with water vapor (introduced using a Nafion membrane humidifier; Perma Pure LLC) to produce $\mathrm{OH}$ radicals in the flow tubes. Both $\mathrm{O}_{3}$ and $\mathrm{OH}$ will oxidize organic species. However, except for $\alpha$ pinene experiments performed at low $\mathrm{OH}$ concentrations, $\mathrm{OH}$ was always the principal oxidant. $\mathrm{OH}$ exposures were obtained by measuring the decay of $\mathrm{SO}_{2}$ due to reaction with $\mathrm{OH}$ at specific UV lamp intensities and $\mathrm{O}_{3}$ concentrations (more details provided in the Appendix). Typical $\mathrm{OH}$ concentrations ranged from $\sim 10^{8}$ to $\sim 10^{10}$ molec cm$^{-3}$ and typical $\mathrm{OH}$ exposures ranged from $(2.0 \pm 1.0) \times 10^{10}$ to $(1.8 \pm 0.3) \times 10^{12}$ molec $\mathrm{cm}^{-3} \mathrm{~s}$. Assuming an average atmospheric $\mathrm{OH}$ concentration of $1.5 \times 10^{6} \mathrm{molec} \mathrm{cm}^{-3}$ (Mao 


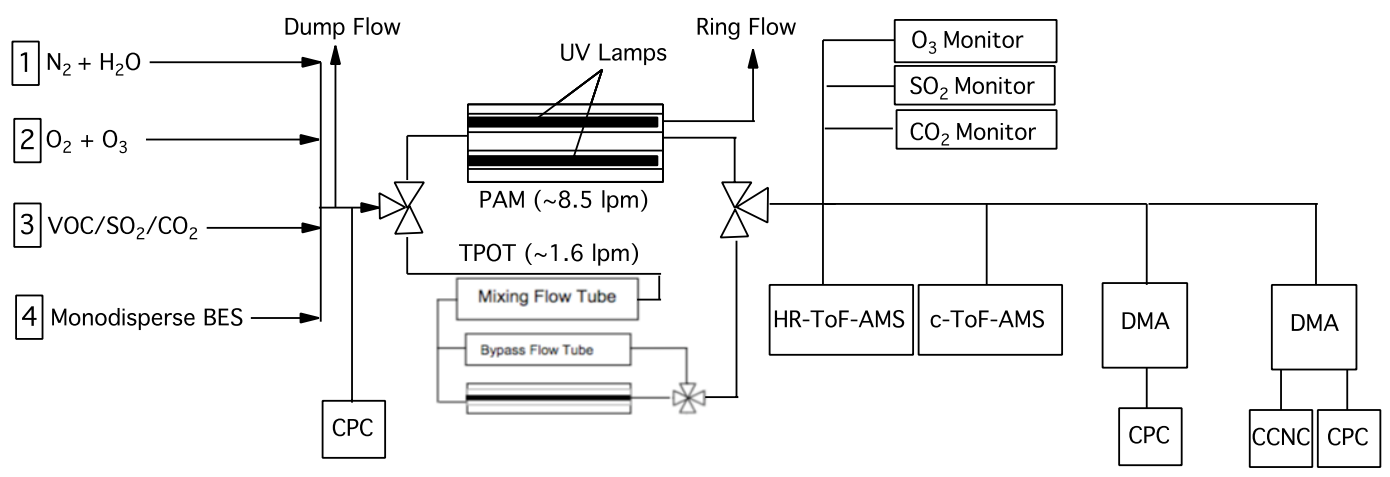

Fig. 1. Schematic of experimental setup. Gas/particle sources and monitoring instruments were shared by the PAM and TPOT flow tubes, with 3-way valves placed upstream and downstream to switch flows and monitoring instruments between reactors. Input lines 1 and 2 provide gases for the production of $\mathrm{OH}$ radicals. Line 3 supplies gas-phase $\alpha$-pinene or $m$-xylene for the production of secondary organic aerosol (SOA), or $\mathrm{SO}_{2}$ for the production of $\mathrm{H}_{2} \mathrm{SO}_{4}$. Line 4 provides monodisperse BES particles.

et al., 2009), this experimental exposure is equivalent to $0.2-$ 14 days of atmospheric oxidation. Prior to an oxidation experiment, each flow reactor was conditioned with $\mathrm{OH}$ radicals until a near-zero particle background was attained.

In the Caltech chamber, $\mathrm{OH}$ radicals were generated by UV photolysis of $\mathrm{H}_{2} \mathrm{O}_{2}(\lambda=350 \mathrm{~nm})$. The Caltech chamber experiments typically generated $[\mathrm{OH}]=3.0 \times 10^{6}$ molec $\mathrm{cm}^{-3}$ for $7-11 \mathrm{~h}$ experimental times, covering oxidant exposures from $7.5 \times 10^{10}$ to $1.2 \times 10^{11} \mathrm{molec} \mathrm{cm}^{-3} \mathrm{~s}$ for a given experiment.

\subsection{Aerosol flow reactors}

\subsubsection{TPOT reactor}

The Toronto Photo-Oxidation Tube (TPOT) reactor combines a $1.6 \mathrm{~L}$ mixing chamber upstream of a $0.8 \mathrm{~L}$ reaction chamber and a $0.8 \mathrm{~L}$ bypass chamber, and is similar to the design of George et al. (2007) except that the outlet of the reaction chamber is orthogonal to the UV lamp. The glass mixing chamber is $50 \mathrm{~cm}$ long $\times 3.6 \mathrm{~cm}$ ID and the glass reaction chamber is $34 \mathrm{~cm}$ long $\times 7.3 \mathrm{~cm}$ ID. A $22.9-\mathrm{cm} \mathrm{O}_{3}$ free mercury pen-ray lamp (UVP) with peak emission intensity at $\lambda=254 \mathrm{~nm}$ is mounted in the center of the reaction chamber. Carrier gas flows of $8.5 \mathrm{lpm} \mathrm{N}_{2}$ and $0.5 \mathrm{lpm} \mathrm{O}$ were used, with $1.6 \mathrm{lpm}$ pulled through the reaction and bypass chambers and $7.4 \mathrm{lpm}$ of excess flow removed prior to the mixing chamber. At these flow conditions, the average plug flow residence time ( $\tau_{\text {plug }}$; volumetric flow rate divided by reactor volume) in the TPOT mixing chamber plus the reaction chamber was $110 \mathrm{~s}$. The UV lamp is surrounded by a quartz sheath tube that was continuously purged with compressed air to cool the lamp. The UV lamp material filtered out $185 \mathrm{~nm}$ light to prevent $\mathrm{O}_{3}$ production. The $\mathrm{OH}$ exposure was varied by changing the $\mathrm{O}_{3}$ concentration input to the mixing chamber.

\subsubsection{PAM reactor}

The Potential Aerosol Mass (PAM) reactor is a horizontal $15 \mathrm{~L}$ glass cylindrical chamber that is $46 \mathrm{~cm}$ long $\times 22 \mathrm{~cm}$ ID. In an effort to reduce wall effects on the photochemistry, the PAM flow reactor was designed with a larger radial/axial dimension ratio and a smaller surface SA/V ratio relative to other flow reactors (e.g. TPOT). Also, the sample flow ( $87 \%$ of total flow) is subsampled from the center of the reactor, with a secondary flow (13\% of total flow) diverted at the exit through an internal perforated ring that dumps air near the reactor walls. The current PAM design is different from the PAM reactor used in Kang et al. (2007), which was a vertical $19 \mathrm{~L}$ Teflon bag with the flow entering the top and a length of $60 \mathrm{~cm}$. Carrier gas flows of $8.5 \mathrm{lpm}$ $\mathrm{N}_{2}$ and $0.5 \mathrm{lpm} \mathrm{O}_{2}$ were used, with $8.5 \mathrm{lpm}$ of flow pulled through the PAM and $0.5 \mathrm{lpm}$ of excess flow removed prior to the reactor. At these flow conditions, the $\tau_{\text {plug }}$ was $106 \mathrm{~s}$, compared to a $\tau_{\text {plug }}$ of $240 \mathrm{~s}$ used by Kang et al. (2007). Four mercury lamps (BHK Inc.) with peak emission intensity at $\lambda=254 \mathrm{~nm}$ are mounted in teflon-coated quartz cylinders inside the chamber. The lamp-mounting cylinders were continually purged with $\mathrm{N}_{2}$ to prevent $\mathrm{O}_{3}$ formation and remove outgassing compounds. Unlike the TPOT and the PAM chamber in Kang et al. (2007), the $\mathrm{OH}$ exposure in the PAM was varied by changing the UV light intensity via stepping the lamp voltages between 0 and $110 \mathrm{~V}$.

\subsection{Flow tube residence time distributions}

Flow tube residence time distributions (RTDs) for gas-phase species were characterized by introducing 10 - and 30 -s pulses of $\mathrm{CO}_{2}$ and $\mathrm{SO}_{2}$ into the flow tubes. $\mathrm{CO}_{2}$ and $\mathrm{SO}_{2}$ were used as surrogate wall-inert and wall-adhering species. Prior to $\mathrm{SO}_{2}$ pulsed inputs, flow tube walls were passivated as much as possible by flowing $\mathrm{SO}_{2}$ until the measured concentration was constant, at which point the flow was removed 
and the signal returned close to background. Pulses were obtained by opening and closing a mass-flow controller (MKS Instruments), and the $\mathrm{CO}_{2}$ or $\mathrm{SO}_{2}$ concentration exiting the flow tube was measured immediately downstream. Tensecond pulses of 145-nm BES particles were used to characterize RTDs for condensed-phase species. BES pulses were obtained by applying and removing voltage to a differential mobility analyzer (DMA) column, and the particle concentration exiting the flow tube was measured with a CPC. In a separate test, we verified time definition of the 10 -s pulses by transmitting the gas flow through straight copper tubing. The pulses were sharp on the timescale of the flow tube RTDs.

\subsection{Particle generation}

In heterogeneous oxidation experiments, BES aerosols were generated by heating liquid BES to $145^{\circ} \mathrm{C}$ inside a nucleator flask. Following George et al. (2009), $145 \mathrm{~nm}$ BES particles were size-selected with a DMA (TSI 3071A). The DMA sheath and excess flows were balanced at $10 \mathrm{lpm}$. A $1.2 \mathrm{lpm}$ monodisperse flow of BES particles was introduced into the PAM or TPOT using input line 4 (Fig. 1).

SOA was generated via gas-phase oxidation of $m$-xylene or $\alpha$-pinene followed by homogeneous nucleation. Similarly, sulfuric acid $\left(\mathrm{H}_{2} \mathrm{SO}_{4}\right)$ particles were generated by $\mathrm{OH}$ oxidation of $\mathrm{SO}_{2}$. The gas-phase species were introduced into the reactor at controlled rates using a mass-flow controller. Because of greater wall interactions in the SOA formation experiments in the TPOT, higher concentrations of $m$-xylene and $\alpha$-pinene were introduced to the TPOT (262$263 \mathrm{ppb})$ than the PAM (78-88 ppb) to achieve sufficient signal-to-noise ratio in the detection of SOA particles. Caltech chamber SOA was generated from initial $m$-xylene and $\alpha$-pinene concentrations that ranged from $14-48 \mathrm{ppb}(\mathrm{Ng}$ et al., 2007a,b). Flow tube- and smog chamber-generated SOA was formed under low- $\mathrm{No}_{\mathrm{x}}$ conditions.

\subsection{Particle monitoring and analysis}

Immediately downstream of each flow tube, annular denuders loaded with silica gel dessicant and Carulite 200 catalyst (Carus Corp.) removed water $(\mathrm{RH}<20 \%)$ and ozone (denuding efficiency $>80 \%$ ) prior to measurements. Particle number concentrations and size distributions were measured with a TSI scanning mobility particle sizer (SMPS). Bulk aerosol mass spectra of the aerosol were measured with Aerodyne compact and high-resolution time-of-flight aerosol mass spectrometers (c-ToF-AMS, HR-ToF-AMS; Drewnick et al., 2005; DeCarlo et al., 2006). Elemental analysis (Aiken et al., 2008) was performed on the HR-ToF-AMS data to determine the aerosol hydrogen-to-carbon $(\mathrm{H} / \mathrm{C})$ and oxygen-to-carbon $(\mathrm{O} / \mathrm{C})$ ratios, the latter of which was used as a proxy for the aerosol carbon oxidation state (Kroll et al., 2009). For experiments where HR-ToF-AMS data was unavailable, we applied HR-ToF-AMS-derived calibration factors relating the $\mathrm{O} / \mathrm{C}$ ratio to the fraction of organic signal at $m / z=44\left(f_{44}\right)$ to c-ToF-AMS measurements. These calibrations are shown in Fig. A1.

$\mathrm{CCN}$ activity of particles was measured with a Droplet Measurement Technologies CCN Counter (Roberts and Nenes, 2005). The fraction of activated particles was determined by measuring total particle concentrations with a CPC (TSI 3022A) colocated with the CCN Counter (hereafter referred to as "CCNC"). A DMA upstream of the CCNC and CPC was used to select a dry mobility diameter $\left(D_{\mathrm{m}}\right)$ of $145 \mathrm{~nm}$ for oxidized BES particles and $50 \mathrm{~nm}$ for $m$-xylene/ $\alpha$-pinene SOA particles. For each $D_{\mathrm{m}}$, the CCNC column temperature gradient was systematically varied between $0.1-1.5 \%$ water vapor supersaturation or until $100 \%$ activation was reached, whichever occurred first. $\mathrm{CCN}$ activity was characterized in terms of the hygroscopicity parameter $\kappa$ as defined by Petters and Kreidenweis (2007). Example $\mathrm{CCN}$ activation curves are shown in Fig. A2.

SOA yields were calculated from the ratio of aerosol mass formed to precursor gas reacted. We estimated the mass of precursor gas reacted from the bimolecular rate constants of $m$-xylene $+\mathrm{OH}, \alpha$-pinene $+\mathrm{OH}$, and $\alpha$-pinene $+\mathrm{O}_{3}$ (Atkinson, 1986). These calculations suggested that about $40 \%-$ $100 \%$ of the m-xylene and $80 \%-100 \%$ of the $\alpha$-pinene reacted, depending on the flow tube $\mathrm{OH}$ exposure. The aerosol mass was calculated from the integrated particle volume and the effective particle density $\left(\rho=D_{\mathrm{va}} / D_{\mathrm{m}}\right)$, where $D_{\mathrm{va}}$ is the mean vacuum aerodynamic diameter and $D_{\mathrm{m}}$ is the electric mobility diameter. Yields were corrected for UV lamp-induced temperature increases in the PAM by applying yield corrections of -0.02 per degree $\mathrm{K}$ of temperature rise (Stanier et al., 2007; Qi et al., 2010) relative to room temperature. These temperature corrections typically ranged from 10-20\%. Caltech smog chamber yields were corrected for wall losses using size-dependent ammonium sulfate wallloss measurements. The magnitude of these wall loss corrections typically ranged from 10-30\%.

\section{Results and discussion}

This study provides intercomparison measurements of aerosol $\mathrm{O} / \mathrm{C}$ and $\mathrm{H} / \mathrm{C}$ ratios, aerosol $\mathrm{CCN}$ activity, and secondary aerosol yields. We expect that two fundamental properties of the different systems will most strongly affect aerosol measurements: (1) wall interactions and (2) residence time distributions (RTDs) of gases and particles in the reactors. Wall interactions (gas and particle) are influenced by a combination of reactor $\mathrm{SA} / \mathrm{V}$ ratio and average residence time, and influence the measured yields of oxidation products. The PAM is designed to minimize wall interactions, as compared with the TPOT. Specifically, the PAM has a SA/V ratio $\sim 10 \times$ lower than the TPOT while the average TPOT and PAM residence times are similar, the PAM has a larger radius which minimizes interactions with the 
walls due to diffusion, and the PAM subsamples flow from the center of the tube whereas the TPOT samples the total flow. Flow tube transmission efficiency measurements in Sects. 3.1 and 3.2 show the effects of wall interactions on measured gas and particle yields. RTDs are influenced by reactor geometry and flow rate, as characterized by the Reynolds number $(R e)$. Flow is laminar in both the TPOT $(R e=15)$ and PAM $(R e=55)$; however, nonideal flow behaviors in the two systems are expected to produce flow instabilities that broaden the RTD's. Consequently, a precursor introduced to the reactors in the presence of oxidants may sample a wide range of $\mathrm{OH}$ exposures. This may affect the measured chemical composition and CCN activity of SOA particles generated in the flow tubes and compared with the smog chamber. Measurements of gas and particle RTDs are presented in Sect. 3.3. The influence of these two factors on the PAM and TPOT SOA chemistry, CCN activity, and SOA yields are presented in Sects. 3.4 and 3.5. Finally, the Caltech smog chamber SA/V ratio is much lower than in the TPOT and PAM, while the average residence time is much longer. Flow tube - smog chamber intercomparison measurements presented in Sect. 3.5 provide insight into the relative importance of the two factors in influencing SOA chemistry and yields.

\subsection{Flow tube transmission efficiencies}

\subsubsection{Gas-phase transmission efficiencies}

Pulsed inputs of $\mathrm{CO}_{2}$ and $\mathrm{SO}_{2}$ (10 and $30 \mathrm{~s}$ in duration) were used to measure the transmission efficiencies of inert $\left(\mathrm{CO}_{2}\right)$ and wall-adhering $\left(\mathrm{SO}_{2}\right)$ gases. Because $\mathrm{SO}_{2}$ can adhere to walls, the flow tubes were passivated prior to measurements as discussed in Sect. 2.3. For each gas-phase species, transmission efficiency was measured for 7-10 pulses. The measured $\mathrm{CO}_{2}$ transmission efficiency was $0.97 \pm 0.10$ for the TPOT and $0.91 \pm 0.09$ for the PAM (uncertainties represent $\pm 1 \sigma$ in measurements unless otherwise noted). The $\mathrm{SO}_{2}$ transmission efficiency was $0.45 \pm 0.13$ for the TPOT and $1.2 \pm 0.4$ for the PAM. Within measurement uncertainty, transmission efficiency was independent of pulse duration and approximately unity for both flow tubes with the exception of $\mathrm{SO}_{2}$ in the TPOT. Comparing $\mathrm{SO}_{2}$ and $\mathrm{CO}_{2}$ transmission efficiencies suggests that $\mathrm{SO}_{2}$ wall loss is negligible in the PAM but is significant $(\sim 55 \%)$ in the TPOT for pulsed experiments. The significant, irreversible wall loss of $\mathrm{SO}_{2}$ in the TPOT for this study was likely due to a chemical adsorption/reaction process that was not fully passivated at the time of the experiment. If this process has a constant $\mathrm{SO}_{2}$ uptake rate, it should not affect our interpretations of the residence time distribution measurements.

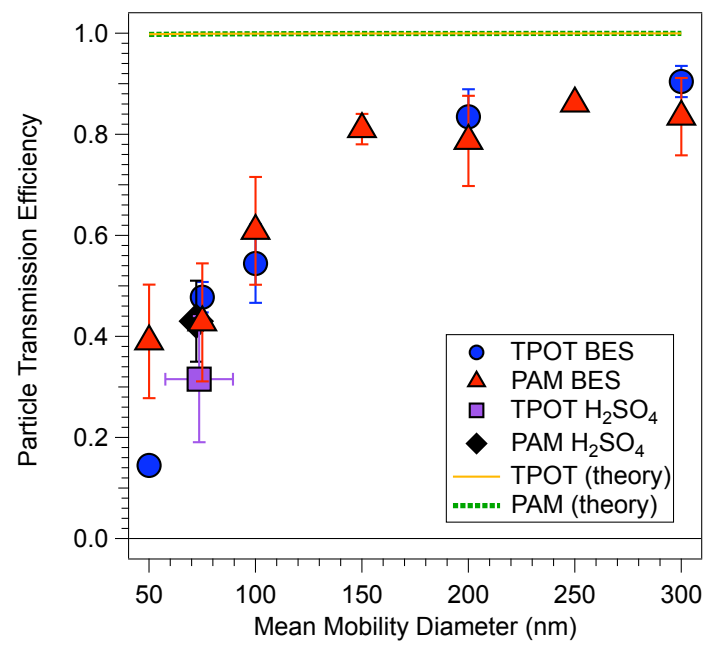

Fig. 2. Measured particle transmission efficiency of TPOT and PAM flow tubes as a function of mean volume-weighted mobility diameter for bis(2-ethylhexyl) sebacate (BES; circles and triangles) and sulfuric acid $\left(\mathrm{H}_{2} \mathrm{SO}_{4}\right.$; square and diamond). $\mathrm{H}_{2} \mathrm{SO}_{4}$ particles were formed inside the flow tubes from $\mathrm{SO}_{2}$ oxidation. Theoretical size-dependent particle transmission efficiencies are also shown for the TPOT (solid orange line) and PAM (dashed green line).

\subsubsection{Particle transmission efficiency}

Monodisperse BES particles were size-selected with $D_{\mathrm{m}}$ ranging from $50-300 \mathrm{~nm}$ to measure size-dependent particle transmission efficiencies in the flow tubes. Transmission efficiency was calculated from two CPC instruments; one at the input, the other at the output of the flow tubes, that agreed to within $\pm 5 \%$ when sampling the same flow. Figure 2 shows the transmission efficiency of BES particles through the TPOT and PAM as a function of $D_{\mathrm{m}}$. Transmission efficiencies were similar for both instruments from $D_{\mathrm{m}}>75 \mathrm{~nm}$, though the TPOT experienced more particle loss at the smallest particle size $(50 \mathrm{~nm})$. Particle losses through copper tubing upstream and downstream of the flow tubes were negligible. The particle transmission efficiencies for the two systems shown in Fig. 2 have increasing size-dependent trends as simple theory predicts (Hinds, 1999); however, the magnitudes of measured particle losses are significantly greater than predicted by theory. The reason for the discrepancy may be due to (a) expansions and contractions in the flow tube designs that are not accounted for in the simple theory and may induce convection or dead volume in the flow tubes, or (b) the non-conducting Pyrex material of both flow tubes may induce greater particle losses due to electrostatic deposition.

\section{2 $\mathrm{H}_{2} \mathrm{SO}_{4}$ yield measurements}

$\mathrm{H}_{2} \mathrm{SO}_{4}$ yield measurements were chosen to evaluate the measurement of secondary aerosol yields in the flow systems. 
$\mathrm{SO}_{2}$ oxidation is a relatively simple system with a single rate-limiting step in the presence of water vapor, has a known rate constant, and generates a well-characterized binary component particle $\left(\mathrm{H}_{2} \mathrm{SO}_{4}\right.$ and $\left.\mathrm{H}_{2} \mathrm{O}\right)$. However, it may not be a perfect surrogate for SOA because the wall loss behavior of the product gases (i.e., $\mathrm{H}_{2} \mathrm{SO}_{4}$ vapor and semivolatile organic compounds) may differ. The transmission efficiency of $\mathrm{H}_{2} \mathrm{SO}_{4}$ particles was calculated from the ratio of the measured aerosol mass to the theoretical $\mathrm{H}_{2} \mathrm{SO}_{4}$ aerosol yield from the known $\mathrm{SO}_{2}-\mathrm{OH}$ reaction. Because the $\mathrm{H}_{2} \mathrm{SO}_{4}$ mass measurement includes water taken up by the $\mathrm{H}_{2} \mathrm{SO}_{4}$ particles, calculations were performed to extract the dry $\mathrm{H}_{2} \mathrm{SO}_{4}$ mass from $\mathrm{H}_{2} \mathrm{SO}_{4}-\mathrm{H}_{2} \mathrm{O}$ particles as discussed in Appendix A. Higher $\mathrm{SO}_{2}$ concentrations were used in the TPOT to compensate for larger $\mathrm{SO}_{2}$ wall losses: $77-84 \mathrm{ppb}$ in the TPOT and 10-62 ppb in the PAM.

Two trends were observed in both flow tubes. First, at a specific $\mathrm{OH}$ concentration, increasing the $\mathrm{SO}_{2}$ concentration increased the transmission efficiency of $\mathrm{H}_{2} \mathrm{SO}_{4}$ particles because a smaller fraction of $\mathrm{SO}_{2}$ and $\mathrm{H}_{2} \mathrm{SO}_{4}$ vapor was required to passivate the walls. Second, $\mathrm{H}_{2} \mathrm{SO}_{4}$ particle transmission efficiency was affected by the $\mathrm{OH}$ concentration. At low $\mathrm{OH}$ concentration, the $\mathrm{SO}_{2}$ lifetime was longer ( $\tau \sim 140 \mathrm{~s}$ ) and $\mathrm{H}_{2} \mathrm{SO}_{4}$ aerosol yield was more affected by $\mathrm{SO}_{2}$ and $\mathrm{H}_{2} \mathrm{SO}_{4}$ vapor wall loss. At high $\mathrm{OH}$ concentration, $\mathrm{SO}_{2}$ was oxidized more quickly ( $\tau \sim 30 \mathrm{~s}$ ), and $\mathrm{H}_{2} \mathrm{SO}_{4}$ aerosol yield was less affected by losses of $\mathrm{SO}_{2}$ and $\mathrm{H}_{2} \mathrm{SO}_{4}$ vapor to the walls. As the $\mathrm{OH}$ exposure was increased from about $4 \times 10^{11}$ molec cm $^{-3} \mathrm{~s}$ to $1.8 \times 10^{12}$ molec cm $\mathrm{cm}^{-3} \mathrm{~s}$ in the TPOT, the $\mathrm{H}_{2} \mathrm{SO}_{4}$ mean volume-weighted $D_{\mathrm{m}}$ increased from $50 \mathrm{~nm}$ to $86 \mathrm{~nm}$ while the particle transmission efficiency increased from 0.14 to 0.44 . Over a similar $\mathrm{OH}$ exposure range in the PAM, the mean $\mathrm{H}_{2} \mathrm{SO}_{4} D_{\mathrm{m}}$ increased from $65 \mathrm{~nm}$ to $75 \mathrm{~nm}$ while the particle transmission efficiency increased from 0.30 to 0.51 . Assuming typical experimental conditions of $10^{5}$ particles $\mathrm{cm}^{-3}$ with a mean diameter of $75 \mathrm{~nm}$ and a gas-phase diffusion coefficient of $0.1 \mathrm{~cm}^{2} \mathrm{~s}^{-1}$, the characteristic timescale for condensation of $\mathrm{H}_{2} \mathrm{SO}_{4}$ vapors onto preexisting particles was $\sim 50 \mathrm{~s}$. Timescales for gas-phase diffusional wall losses were $\sim 70 \mathrm{~s}$ in the TPOT and $\sim 600 \mathrm{~s}$ in the PAM. These calculations indicate that flow tube walls were competitive with $\mathrm{H}_{2} \mathrm{SO}_{4}$ particles as a sink for $\mathrm{H}_{2} \mathrm{SO}_{4}$ vapors in the TPOT and significantly less competitive with $\mathrm{H}_{2} \mathrm{SO}_{4}$ particles in the PAM.

Average $\mathrm{H}_{2} \mathrm{SO}_{4}$ particle transmission efficiencies in the TPOT and PAM are plotted in Fig. 2 as a function of mean volume-weighted mobility diameter. The particle transmission efficiencies through the flow tubes are shown to be similar for BES and $\mathrm{H}_{2} \mathrm{SO}_{4}$ particles. For the test conditions here, the yields for $\mathrm{SO}_{2}$ oxidation $\left(\mathrm{H}_{2} \mathrm{SO}_{4}\right.$ particle formation) saturate at particle transmission efficiencies of $\sim 0.5$ due to size-dependent particle losses in the flow reactors. Thus, yield measurements of $\mathrm{SO}_{2}$ oxidation in the flow tubes is a function of $\mathrm{SO}_{2}$ and $\mathrm{H}_{2} \mathrm{SO}_{4}$ loss to walls (until saturated) and the depositional loss of the resulting particles inside the reactors prior to detection. SOA reaction yields measured in flow tubes reactors will have similar experimental dependencies.

\subsection{Flow tube residence time distributions (RTDs)}

Residence time distributions (RTDs) of the two flow tube reactor designs were characterized with an inert gas $\left(\mathrm{CO}_{2}\right)$, a wall-adhering gas $\left(\mathrm{SO}_{2}\right)$, and a low-volatility spherical particle (BES). Figure $3 \mathrm{a}$ and $\mathrm{b}$ show representative residence time distribution measurements for $\mathrm{CO}_{2}, \mathrm{SO}_{2}$ and $\mathrm{BES}$ pulsed inputs to the TPOT and the PAM, respectively. The pulses were produced as discussed in Sect. 2.3, with each species added individually. Figure $3 \mathrm{c}$ compares the measured RTDs for $\mathrm{CO}_{2}$ in the TPOT and the PAM. Three sets of observations are evident from Fig. 3.

The first observations relate to the shape and width of the RTDs measured with $\mathrm{CO}_{2}$. Figure $3 \mathrm{c}$ shows measured RTDs for $\mathrm{CO}_{2}$ in the TPOT and in the PAM plotted with theoretical RTDs for reactors with ideal plug flow and ideal laminar flow characteristics. The theoretical RTDs were calculated assuming an average residence time of $100 \mathrm{~s}$ (compared with 110 and $106 \mathrm{~s}$ plug flow residence times for the TPOT and PAM, respectively). Under plug flow conditions, the RTD is the duration of the pulse delayed by the transit time through the flow tube. Under laminar flow conditions, the shortest transit time through the flow tube is half of the average residence time. The initial shapes of both flow tube RTDs are similar to the theoretical laminar flow predictions, though the measured RTDs occur earlier in time, and both measured RTDs exhibit tailing at longer times. To gain a fuller understanding of the flow conditions in both systems, we modelled the RTDs as a laminar flow broadened by axial and radial diffusion using a Taylor dispersion model (Taylor, 1953). A best fit to our measurements required that we assumed two flow regimes: (1) a primary component that passes through the reactors without recirculation, and (2) a secondary component that is slower and more diffuse due to convectioninduced recirculation or entrainment in dead volumes within the reactors. The flow model results are shown by the dashed black traces in Fig. 3c. The model, described in Appendix A, predicts less recirculation (i.e., smaller secondary flow component) in the TPOT than in the PAM (Fig. A3), which is in agreement with the observations that show narrower RTDs in the TPOT.

The second set of observations from Fig. 3 are that the RTDs from the $\mathrm{SO}_{2}$ pulses are delayed relative to the $\mathrm{CO}_{2}$ pulses. In the absence of wall interactions, the $\mathrm{CO}_{2}$ and $\mathrm{SO}_{2}$ RTDs are expected to be the same. Therefore, this delay indicates $\mathrm{SO}_{2}$-wall interactions. In the TPOT, the $\mathrm{SO}_{2}$ pulse was delayed relative to the $\mathrm{CO}_{2}$ pulse by $40-50 \mathrm{~s}$ (refer to Appendix A). A delay was also observed in the PAM, but it was smaller $(\sim 20 \mathrm{~s})$ due to the lower SA/V ratio. The $\mathrm{SO}_{2}$ RTD experiments show unambiguous wall effects on gas-phase precursors in the flow tube reactor designs. How 


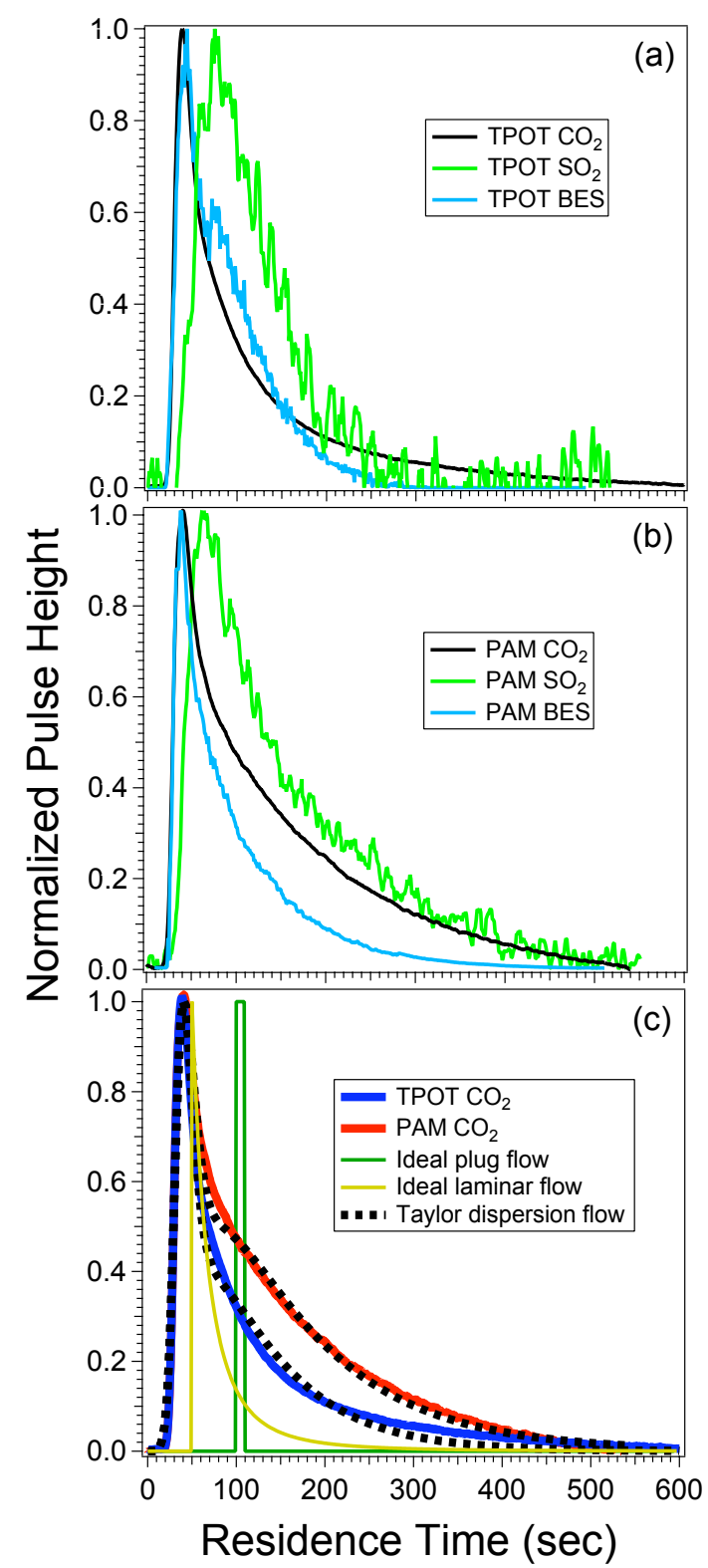

Fig. 3. Residence time distribution (RTD) measurements in the TPOT and PAM flow tubes. UV lamps were on during measurements. (a) $\mathrm{CO}_{2}, \mathrm{SO}_{2}$, and BES RTDs in the TPOT (b) $\mathrm{CO}_{2}, \mathrm{SO}_{2}$, and BES RTDs in the PAM (c) $\mathrm{CO}_{2}$ RTDs in the TPOT and PAM. Theoretical plug flow and ideal laminar flow RTDs are plotted assuming an average residence time of $100 \mathrm{~s}$. Dashed lines represent Taylor dispersion flow RTDs that were fit to the measurements (described in Appendix A).

these wall effects impact chemical and yield measurements of secondary organic aerosol (SOA) will depend upon oxidation rates and accommodation coefficients of the precursor and intermediate gases by the walls.

The third set of observations are that the BES RTDs were narrower than the corresponding $\mathrm{CO}_{2}$ and $\mathrm{SO}_{2}$ RTDs in both flow tubes. This was likely due to either (a) poor mixing of the particles into the carrier gas flow prior to the reactors, or (b) greater fractional particle losses for particles entrained in convection currents/dead volumes (i.e., longer residence times in reactors with more potential for wall interactions). For the PAM, the difference between BES particles and gasphase species was more pronounced than in the TPOT, possibly because the mixing time upstream of the PAM was significantly shorter or because longer residence times due to recirculation of the flow resulted in higher particle losses in the PAM than in the TPOT.

The measured RTDs have several implications for accurately comparing aerosol chemistry measurements from one system to another. The measured RTDs for these flow tube systems are asymmetric in time with a sharp peak at $\leq 50 \%$ of the plug flow residence time and a significant tail to times greater than $\tau_{\text {plug }}$. Pulsed aerosol chemistry experiments with high time resolution detection techniques may provide more accurate results over a range of $\mathrm{OH}$ exposures than steadystate flowing experiments. Further, the wall-adhering $\mathrm{SO}_{2}$ experiments show that the average (RTD-weighted mean) residence times are greater than that predicted from the $\mathrm{CO}_{2}$ experiments, indicating that the $\mathrm{OH}$ exposure is dependent upon the precursor gas wall interactions (i.e., volatility, mass accommodation, and SA/V ratio of the system). Finally, the BES experiments suggest a similiar asymmetry in the measured RTDs and corresponding residence times in flow tube reactors for heterogeneous reaction experiments, with the added uncertainty of increasing particle losses with residence time due to recirculation.

\subsection{O/C ratio, $\mathrm{H} / \mathrm{C}$ ratio, and $\mathrm{CCN}$ activity of oxidized BES}

\subsection{1 $\mathrm{O} / \mathrm{C}$ and $\mathrm{H} / \mathrm{C}$ ratios}

Figure $4 \mathrm{a}$ and $\mathrm{b}$ show the evolution of the aerosol oxygento-carbon $(\mathrm{O} / \mathrm{C})$ and hydrogen-to-carbon $(\mathrm{H} / \mathrm{C})$ ratios for BES particles $\left(D_{\mathrm{m}}=145 \mathrm{~nm}\right)$ as a function of $\mathrm{OH}$ exposure. The equivalent atmospheric exposure, expressed in days at $[\mathrm{OH}]=1.5 \times 10^{6}$ molec $\mathrm{cm}^{-3}$, is shown on the top axis. The measured $\mathrm{O} / \mathrm{C}$ and $\mathrm{H} / \mathrm{C}$ ratios of unoxidized $\mathrm{BES}$ were 0.04 and 1.96 , compared to a measured $\mathrm{O} / \mathrm{C}$ ratio of 0.05 by Aiken et al. (2007) and atomic O/C and $\mathrm{H} / \mathrm{C}$ ratios of 0.15 and $1.92\left(\mathrm{C}_{26} \mathrm{H}_{50} \mathrm{O}_{4}\right)$. As the $\mathrm{OH}$ exposure was increased, the measured $\mathrm{O} / \mathrm{C}$ ratio increased to $0.20 \mathrm{in}$ the TPOT and the PAM. The corresponding H/C ratios decreased to 1.78 in the flow tubes. For the most part, the agreement between the two flow reactors was excellent. The highest $\mathrm{O} / \mathrm{C}$ ratio was reached at a slightly lower $\mathrm{OH}$ exposure in the PAM $\left(1.4 \times 10^{12}\right.$ molec $\left.\mathrm{cm}^{-3} \mathrm{~s}\right)$ than in the TPOT $\left(1.8 \times 10^{12}\right.$ molec $\left.\mathrm{cm}^{-3} \mathrm{~s}\right)$. This observation is consistent with the differences in measured RTDs for the two flow reactors discussed above. 


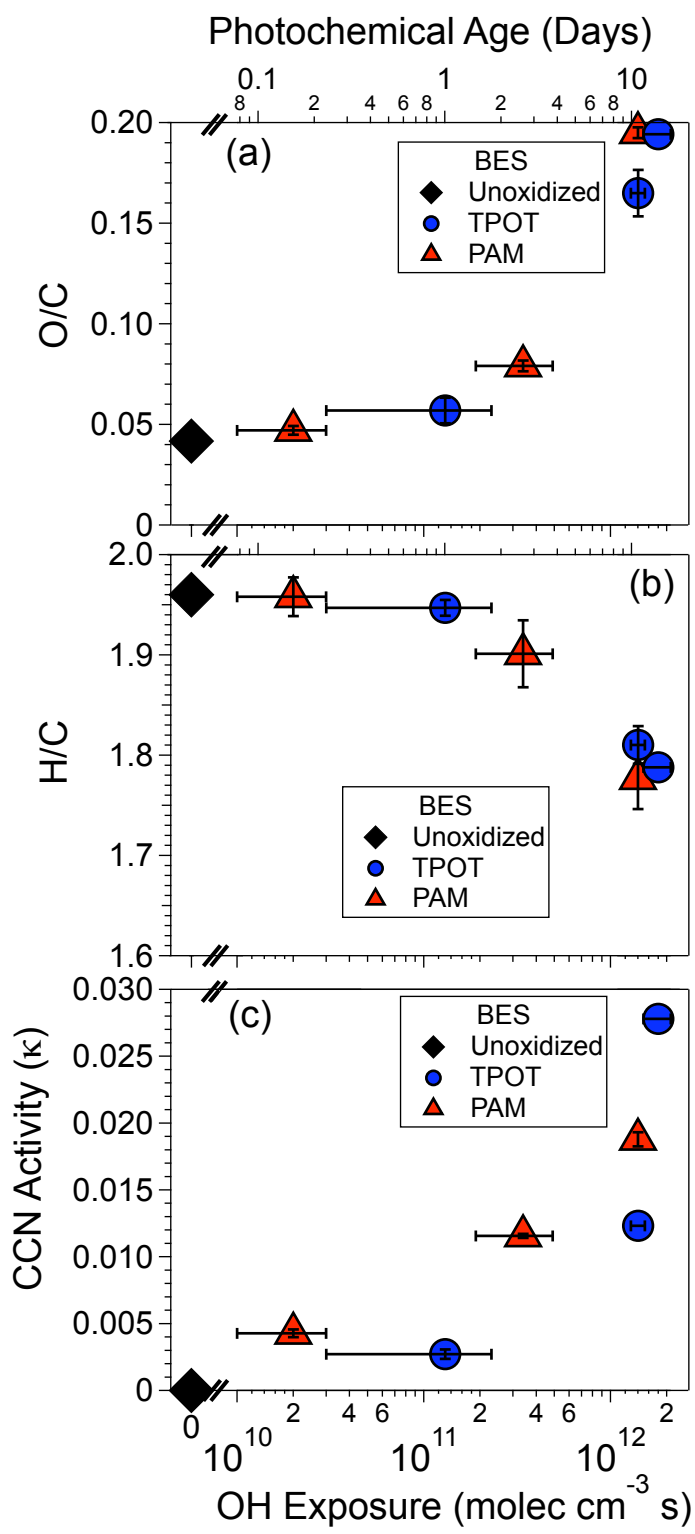

Fig. 4. Aerosol (a) oxygen-to-carbon (O/C) and (b) hydrogen-tocarbon $(\mathrm{H} / \mathrm{C})$ ratios of oxidized 145-nm BES particles as a function of $\mathrm{OH}$ exposure. Unoxidized BES is shown with a black diamond marker. (c) $\mathrm{CCN}$ activity $(\kappa)$ of oxidized BES particles as a function of $\mathrm{OH}$ exposure. Equivalent atmospheric photochemical age is shown on the top axis assuming an average $\mathrm{OH}$ concentration of $1.5 \times 10^{6}$ molec $\mathrm{cm}^{-3}$. Error bars indicate calibration uncertainty in $\mathrm{OH}$ exposure, $\pm 1 \sigma$ in $\mathrm{O} / \mathrm{C}$ and $\mathrm{H} / \mathrm{C}$ measurements, and $\pm 1 \sigma$ in $\mathrm{CCN} \kappa$ measurements.

\subsubsection{CCN activity}

Figure $4 \mathrm{~b}$ shows results of $\mathrm{CCN}$ activity studies expressed in terms of the hygroscopicity parameter $\kappa$ of heterogeneously oxidized BES particles as a function of $\mathrm{OH}$ exposure. As expected, $\kappa$ increased as the $\mathrm{OH}$ exposure and $\mathrm{O} / \mathrm{C}$ ratio increased (Petters et al., 2006; Massoli et al., 2010). The $\kappa$ values for particles with $\mathrm{O} / \mathrm{C}>0.08$ were between 0.012 0.028 . At an $\mathrm{OH}$ exposure of $\sim 1.4 \times 10^{12} \mathrm{molec} \mathrm{cm}^{-3} \mathrm{~s}$, the $\kappa$ values measured with the two flow tubes were within $50 \%$ of each other. However, at lower $\mathrm{OH}$ exposures for $\mathrm{O} / \mathrm{C}<0.08$, the $\kappa$ values measured in the two flow tubes diverged considerably, differing by as much as $100 \%$. Under the low oxidation levels with the large $\kappa$ discrepancies, the $\mathrm{CCN}$ activation curves for both systems are broad (Fig. A2). The $\kappa$ discrepancy and broad $\mathrm{CCN}$ activation curves can both be explained by the fact that (1) heterogeneous oxidation timescales of BES particles ( 200-3000 s; George et al., 2007; Lambe et al., 2009) are slow compared to average particle residence times in the flow tubes, and (2) the RTDs for BES particles differ between the PAM and the TPOT at longer residence times (Figs. 3 and A3). Therefore, because the heterogeneous oxidation rates are slow and the PAM exhibits a longer tail in the measured BES RTD, the BES particles experience more oxidation in the PAM for essentially the same flow and average $\mathrm{OH}$ exposure conditions. The difference in the oxidation level of the BES particles for the low $\mathrm{OH}$ exposure conditions is highlighted by the $\mathrm{CCN}$ measurements (Fig. 4b), but is not as obvious in the $\mathrm{O} / \mathrm{C}$ and $\mathrm{H} / \mathrm{C}$ ratio measurements (Fig. 4a). This may be due to different chemical composition that is captured by the $\mathrm{CCN}$ measurements but not the $\mathrm{O} / \mathrm{C}$ and $\mathrm{H} / \mathrm{C}$ ratio measurements.

\subsection{O/C ratio, yield and CCN activity of $m$-xylene and $\alpha$-pinene SOA}

For SOA obtained from $m$-xylene and $\alpha$-pinene, in addition to the data obtained with the TPOT and PAM, published yield data (Ng et al., 2007a,b) and unpublished AMS measurements obtained in the Caltech smog chamber were included in the comparison.

\subsection{1 $\mathrm{O} / \mathrm{C}$ and $\mathrm{H} / \mathrm{C}$ ratios}

Figure 5 shows the $\mathrm{O} / \mathrm{C}$ and $\mathrm{H} / \mathrm{C}$ ratios as a function of $\mathrm{OH}$ exposure for $m$-xylene and $\alpha$-pinene-generated SOA produced in the TPOT, PAM and Caltech smog chamber. The equivalent atmospheric photochemical age at $[\mathrm{OH}]=1.5 \times 10^{6}$ molec $\mathrm{cm}^{-3}$ is shown on the top axis. As shown in Fig. 5a at low OH exposure $\left(<10^{11}\right.$ molec cm $\left.^{-3} \mathrm{~s}\right)$, the $\mathrm{O} / \mathrm{C}$ ratio for $m$-xylene SOA generated in the flow tubes was $0.63 \pm 0.03$ in the TPOT and $0.60 \pm 0.01$ in the PAM. The corresponding $\mathrm{H} / \mathrm{C}$ ratios were $1.46 \pm 0.06$ in the TPOT and $1.43 \pm 0.07$ in the PAM (Fig. $5 b$ ). For the smog chambergenerated $m$-xylene SOA, the $\mathrm{O} / \mathrm{C}$ ratio increased from 0.08 to 0.43 as a function of $\mathrm{OH}$ exposure. The higher $\mathrm{O} / \mathrm{C}$ ratio in the flow tube SOA compared to the smog chamber was probably due to faster gas-phase oxidation, resulting in higher levels of oxidation prior to nucleation. As the $\mathrm{OH}$ exposure was increased from $\sim 10^{11}$ to $\sim 10^{12} \mathrm{molec} \mathrm{cm}^{-3} \mathrm{~s}$, the $\mathrm{O} / \mathrm{C}$ ratio of $m$-xylene SOA increased to $0.77 \pm 0.05$ in the TPOT and $1.24 \pm 0.07$ in the PAM. These increases in $\mathrm{O} / \mathrm{C}$ were 


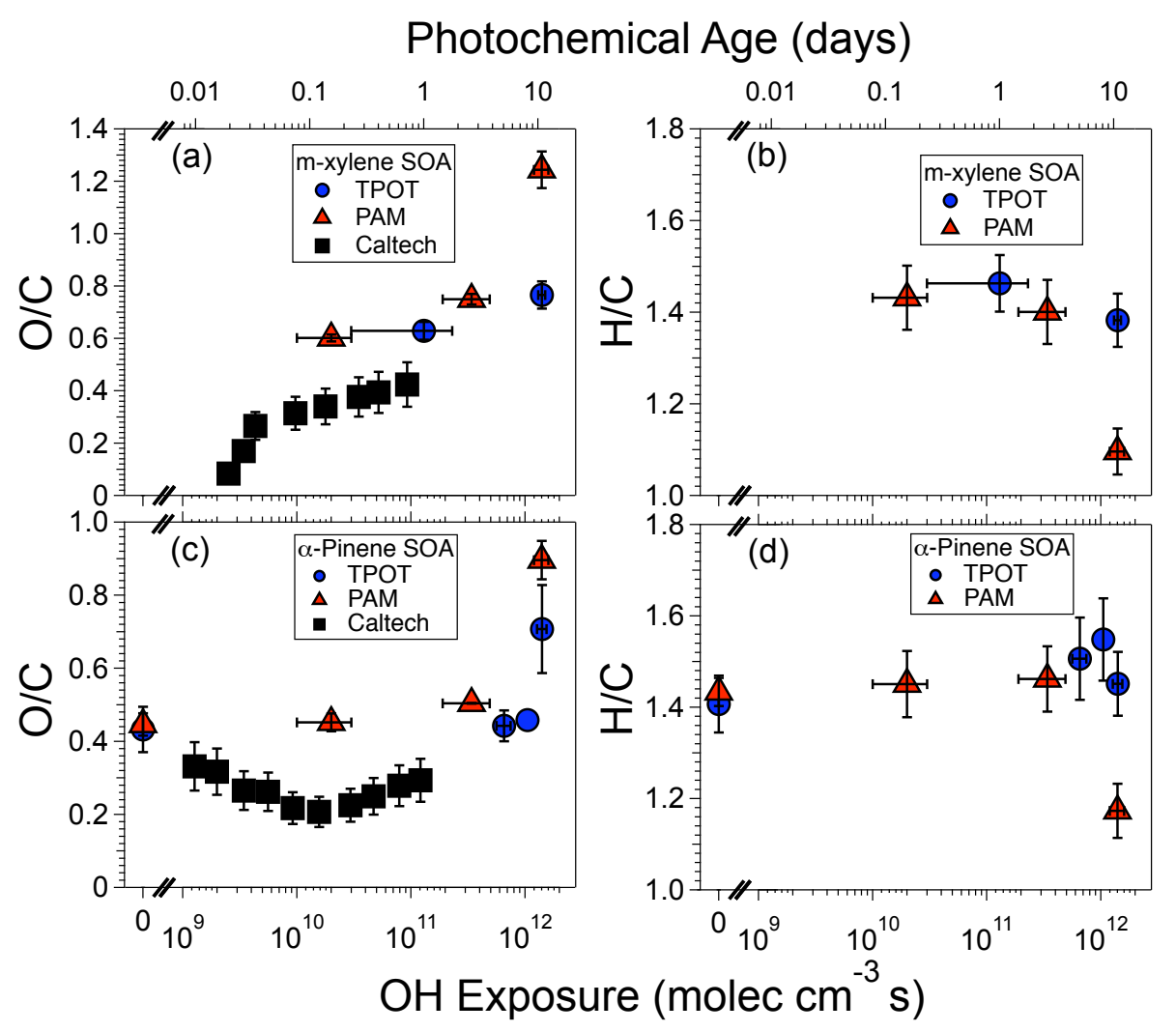

Fig. 5. Aerosol (a) oxygen-to-carbon $(\mathrm{O} / \mathrm{C})$ and (b) hydrogen-to-carbon $(\mathrm{H} / \mathrm{C})$ ratios as a function of $\mathrm{OH}$ exposure for $m$-xylene $\mathrm{SOA}$, along with (c) O/C and (d) H/C ratios as a function of OH exposure for $\alpha$-pinene SOA in the TPOT, PAM and Caltech chamber. Markers at "zero" $\mathrm{OH}$ exposure indicate flow tube ozonolysis conditions with UV lamps turned off. Equivalent atmospheric photochemical age is shown on the top axis assuming an average $\mathrm{OH}$ concentration of $1.5 \times 10^{6} \mathrm{molec} \mathrm{cm}^{-3}$. Error bars indicate calibration uncertainty in $\mathrm{OH}$ exposure, $\pm 1 \sigma$ in flow tube $\mathrm{O} / \mathrm{C}$ and $\mathrm{H} / \mathrm{C}$ ratio measurements, and uncertainty in converting Caltech chamber $\mathrm{m} / \mathrm{z}=44$ measurements to $\mathrm{O} / \mathrm{C}$ ratios.

accompanied by the $\mathrm{H} / \mathrm{C}$ ratio decreasing to $1.38 \pm 0.06$ in the TPOT and $1.10 \pm 0.05$ in the PAM, indicating that the PAM-generated SOA was more oxidized. Differences in the $\mathrm{O} / \mathrm{C}$ and $\mathrm{H} / \mathrm{C}$ ratios of $m$-xylene SOA at $\sim 10^{12} \mathrm{molec}^{-3} \mathrm{~s}$ $\mathrm{OH}$ exposure may be related to different gas-phase residence time distributions (as discussed above) or to different organic aerosol concentrations $\left(C_{\mathrm{OA}}\right)$. Assuming a diffusion coefficient of $0.1 \mathrm{~cm}^{2} \mathrm{~s}^{-1}$ for oxidized vapors, characteristic vapor wall loss timescales were much shorter in the TPOT than in the PAM (Sect. 3.2) despite similar average residence times (Fig. 2). This indicates that walls were a more competitive sink for vapors in the TPOT than in the PAM. In describing the effects of gas-wall partitioning on SOA formation, Matsunaga and Ziemann (2010) treated smog chamber walls as an effective organic aerosol concentration $\left(\mathrm{C}_{\mathrm{W}}\right)$. If the sum of $C_{\mathrm{OA}}$ and $C_{\mathrm{w}}$ was larger in the TPOT than in the PAM, the condensed-phase partitioning of semivolatile compounds with effective saturation concentrations $\left(C^{*}\right.$; Donahue et al., 2006) similar to $C_{\mathrm{OA}}+C_{\mathrm{w}}$ would increase. This would enrich the aerosol with less-oxidized, higher-volatility products having lower $\mathrm{O} / \mathrm{C}$.
In Fig. 5c, the $\mathrm{O} / \mathrm{C}$ ratio for $\alpha$-pinene SOA generated in both flow tubes was $0.45 \pm 0.02$ at low $\mathrm{OH}$ exposures. The corresponding $\mathrm{H} / \mathrm{C}$ ratios were $1.51 \pm 0.09$ in the TPOT and $1.45 \pm 0.07$ in the PAM (Fig. 5d). Smog chamber-generated $\alpha$-pinene SOA had $\mathrm{O} / \mathrm{C}$ ratios ranging from 0.20 to 0.30 . At high $\mathrm{OH}$ exposures, the $\mathrm{O} / \mathrm{C}$ ratio of $\alpha$-pinene SOA increased to $0.70 \pm 0.12$ in the TPOT and $0.90 \pm 0.05$ in the $\mathrm{PAM}$, with corresponding $\mathrm{H} / \mathrm{C}$ ratios of $1.45 \pm 0.07$ in the TPOT and $1.17 \pm 0.06$ in the PAM. As was the case with $\mathrm{m}-$ xylene SOA, differences in $\alpha$-pinene SOA O/C and H/C ratios may be due to the different residence time distributions or to different $C^{*} /\left(C_{\mathrm{OA}}+C_{\mathrm{w}}\right)$ ratios, as well as to different flow tube designs. In the TPOT, the mixing tube upstream of the reactor flow tube (Fig. 1) allowed $\alpha$-pinene and $\mathrm{O}_{3}$ to mix and react prior to $\mathrm{OH}$ exposure, leading to the $\mathrm{OH}$ oxidation of different species. Upstream of the PAM, mixing time prior to $\mathrm{OH}$ exposure is minimized. This is captured by the different evolution of $\mathrm{O} / \mathrm{C}$ and $\mathrm{H} / \mathrm{C}$ with $\mathrm{OH}$ exposure in the TPOT and PAM, which may illustrate the formation of different functional groups as a result of oxidation (Heald et al., 2010). 


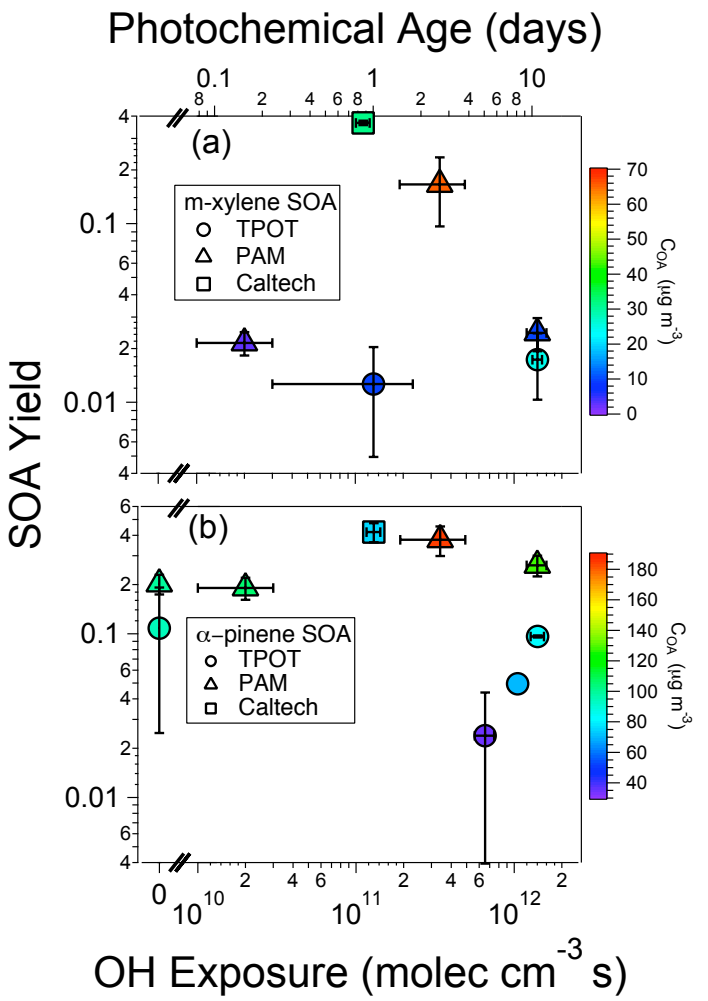

Fig. 6. SOA yield as a function of $\mathrm{OH}$ exposure for (a) $m$-xylene SOA and (b) $\alpha$-pinene SOA generated in the TPOT, PAM and Caltech chamber. Markers at "zero" $\mathrm{OH}$ exposure indicate ozonolysis measurements with flow tube UV lamps turned off. Markers are colored by organic aerosol concentration $\left(C_{\mathrm{OA}}\right)$. Equivalent atmospheric photochemical age is shown on the top axis assuming an average $\mathrm{OH}$ concentration of $1.5 \times 10^{6} \mathrm{molec}^{-3}$. Error bars indicate calibration uncertainty in $\mathrm{OH}$ exposure and $\pm 1 \sigma$ in SOA yield measurements.

\subsubsection{SOA yield}

Figures 6 and 7 show yields of $m$-xylene and $\alpha$-pinene SOA as a function of $\mathrm{OH}$ exposure and $C_{\mathrm{OA}}$, respectively, for the TPOT, PAM and Caltech chamber. Flow tube SOA yields were corrected for size-dependent particle transmission efficiency measurements (Fig. 2), and smog chamber SOA yield were corrected using size-dependent $\left(\mathrm{NH}_{4}\right)_{2} \mathrm{SO}_{4}$ wall loss measurements (Sect. 2.5).

Figure 6 indicates that SOA yield was strongly affected by $\mathrm{OH}$ exposure. SOA yields in the TPOT were lower than in the PAM and Caltech chamber. This is presumably because the higher TPOT SA/V ratio caused greater losses of gasphase precursors and/or oxidation products to the walls, as was observed with $\mathrm{SO}_{2}$ and $\mathrm{H}_{2} \mathrm{SO}_{4}$ (Sects. 3.1.1 and 3.2). For comparable $\mathrm{OH}$ exposures $\left(\sim 10^{11}\right.$ molec $\left.\mathrm{cm}^{-3} \mathrm{~s}\right), \alpha$ pinene SOA yields in the PAM $(0.38 \pm 0.08)$ and Caltech chamber $(0.42 \pm 0.06)$ agreed within $10 \%$. These PAM chamber results are also consistent with those obtained by

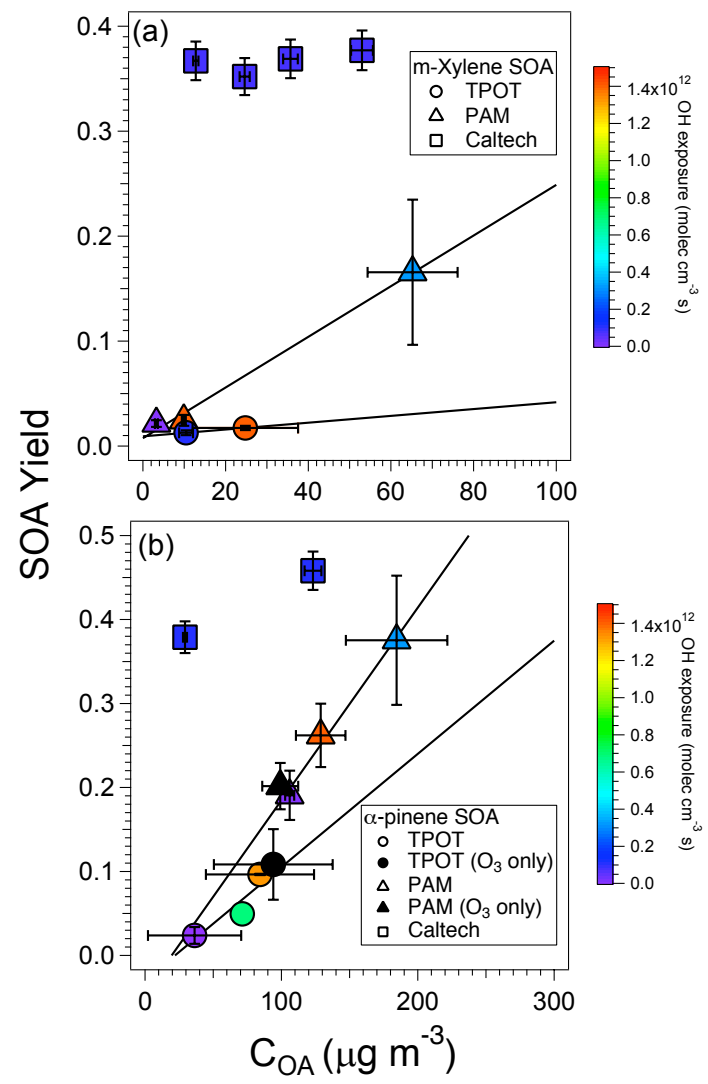

Fig. 7. SOA yield as a function of organic aerosol concentration $\left(C_{\mathrm{OA}}\right)$ for (a) $m$-xylene SOA and (b) $\alpha$-pinene SOA generated in the TPOT, PAM and Caltech smog chamber. Markers are colored by $\mathrm{OH}$ exposure, except for black markers indicating flow tube ozonolysis conditions with UV lamps turned off. Black lines are linear fits to TPOT and PAM measurements to guide the eye. Error bars indicate $\pm 1 \sigma$ in SOA yield and $C_{\mathrm{OA}}$ measurements.

Kang et al. (2007). However, $m$-xylene SOA yields in the PAM $\left(0.17 \pm 0.07 ; \sim 3 \times 10^{11}\right.$ molec $^{-3} \mathrm{~s} \mathrm{OH}$ exposure $)$ and Caltech chamber $\left(0.37 \pm 0.01 ; \sim 1 \times 10^{11}\right.$ molec cm $^{-3} \mathrm{~s}$ $\mathrm{OH}$ exposure) were different. This indicates that yields of $m$-xylene SOA may be more sensitive to $\mathrm{OH}$ concentration, $\mathrm{OH}$ exposure or wall interactions. For lower and higher $\mathrm{OH}$ exposures, yields of PAM $\alpha$-pinene SOA were different $(0.26 \pm 0.04$ and $0.19 \pm 0.03)$ than the maximum measured yield at $3 \times 10^{11}$ molec $\mathrm{cm}^{-3} \mathrm{~s} \mathrm{OH}$ exposure. This was also the case for yields of PAM $m$-xylene SOA, which were $0.024 \pm 0.005$ at lower exposures and $0.022 \pm 0.003$ at higher $\mathrm{OH}$ exposures. This decrease in PAM yields with increasing $\mathrm{OH}$ exposure may be due to SOA fragmentation to smaller, more volatile oxidation products, or to more rapid gas-phase oxidation suppressing aerosol growth (Kroll et al., 2009).

Figure 7 indicates that SOA yield was strongly affected by $C_{\mathrm{OA}}$. Further, at a specific $C_{\mathrm{OA}}, \mathrm{SOA}$ yield increased with decreasing reactor SA/V ratio from the TPOT $\left(2.8 \mathrm{~cm}^{-1}\right)$ to 
the PAM $\left(0.23 \mathrm{~cm}^{-1}\right)$ to the Caltech chamber $\left(0.027 \mathrm{~cm}^{-1}\right)$. The most applicable comparison would use the same precursor concentrations and the same $\mathrm{OH}$ exposure. However, because of experimental constraints, these yield curves were generated using gas-phase precursor mixing ratios of 262$263 \mathrm{ppb}$ in the TPOT, 78-88 ppb in the PAM, and 14-48 ppb in the Caltech chamber. Because SOA yield often increases with increasing precursor concentration (Odum et al., 1996; Kang et al., 2007), trends shown in Fig. 7 would have been even more pronounced if the initial precursor concentrations were similar in the TPOT, PAM and Caltech chamber.

As is evident in Figs. 6 and 7, at comparable $\mathrm{OH}$ exposures, the SOA O/C ratio and yield obtained with the flow tubes are different from those obtained in the smog chamber for $m$-xylene and to a lesser extent for $\alpha$-pinene. While the disagreement in SOA yield between the PAM chamber and the Caltech chamber for $m$-xylene was also seen for the PAM chamber in Kang et al. (2007), the SOA yield for $\alpha$-pinene is within the uncertainties of the SOA yields obtained in the Caltech and Kang et al. (2007) chambers. Oxidation rate, oligomerization reactions, UV lamp intensity/wavelength, and/or wall effects may have influenced SOA yield. Faster gas-phase oxidation relative to nucleation could explain lower yields in the flow tubes than in the smog chamber. Longer oxidation timescales in the smog chamber could favor the formation of oligomers to an extent that is not possible in the flow tubes (e.g. Hallquist et al., 2009 and references therein). UV lamp intensity or wavelength could affect yield of oxidation products with strong UV absorption (e.g. organic peroxides; Presto et al., 2005). The flow tube and Caltech chamber UV lamps have a peak light output at $\lambda=254 \mathrm{~nm}$ and $\lambda=350 \mathrm{~nm}$, respectively. However, if the flow tubes generate SOA that absorbs $254 \mathrm{~nm}$ light, the UV intensity in the TPOT would have to be higher than in the PAM to explain trends shown in Figs. 6 and 7. The UV intensity was not measured in the flow tubes. However, because $\mathrm{OH}$ exposures were similar in both flow tubes using the same $\mathrm{O}_{2}, \mathrm{O}_{3}$ and $\mathrm{H}_{2} \mathrm{O}$ inputs, wall effects seem to have the strongest influence on SOA yield. In particular, it is likely that the results are affected by wall losses of semivolatile oxidation products. More work is necessary to determine the effects of walls on semivolatile gases and particles in all chambers.

\subsubsection{SOA CCN activity}

Figure 8 plots the hygroscopicity parameter $(\kappa)$ of flow tube $m$-xylene and $\alpha$-pinene SOA particles as a function of $\mathrm{OH}$ exposure. The TPOT and PAM measurements agreed within $30 \%$ and $25 \%$ for $m$-xylene and $\alpha$-pinene SOA, respectively. As with oxidized BES particles, $\kappa$ increased with increasing $\mathrm{OH}$ exposure and corresponding $\mathrm{O} / \mathrm{C}$ ratio. For particles generated at an $\mathrm{OH}$ exposure of $\sim 1.5 \times 10^{12} \mathrm{molec} \mathrm{cm}^{-3} \mathrm{~s}$, PAM SOA had a slightly higher $\mathrm{O} / \mathrm{C}$ ratio and higher $\kappa$ than TPOT SOA. This is consistent with more highly-oxidized

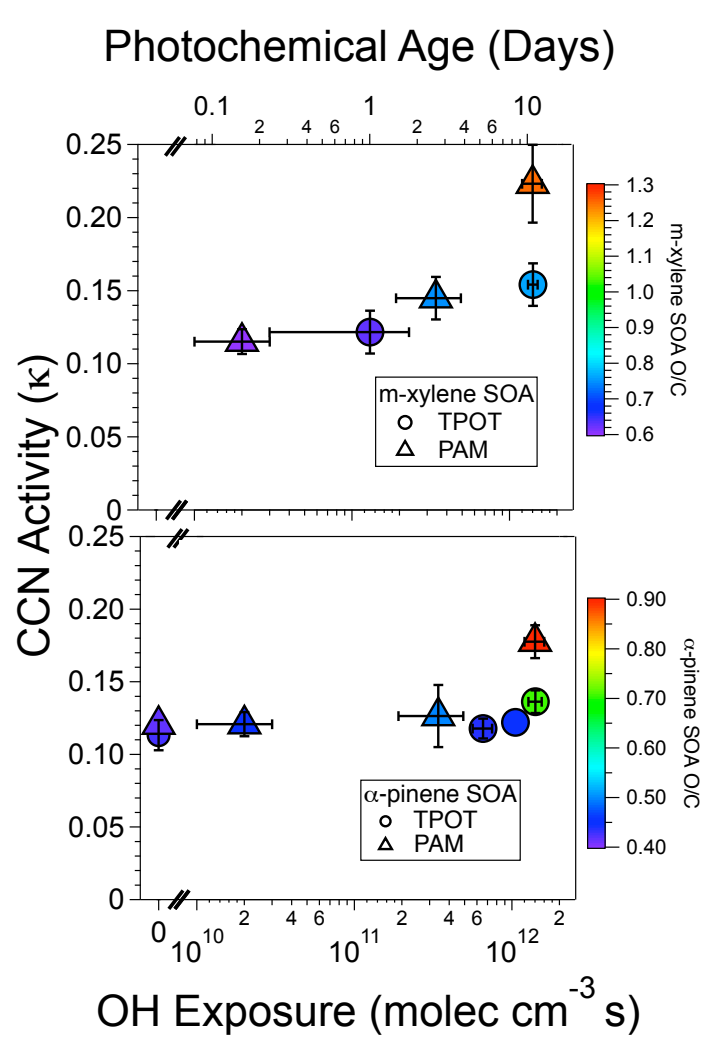

Fig. 8. CCN activity $(\kappa)$ of SOA particles as a function of $\mathrm{OH}$ exposure; data at "zero" $\mathrm{OH}$ exposure was generated from ozonolysis reactions with flow tube UV lamps turned off. Particles were size-selected at $D_{\mathrm{m}}=50 \mathrm{~nm}$ for CCN measurements. CCN activity of (a) $m$-xylene SOA particles and (b) $\alpha$-pinene SOA particles in the TPOT and PAM are shown. Markers are colored by O/C, and equivalent atmospheric photochemical age is shown on the top axis assuming an average $\mathrm{OH}$ concentration of $1.5 \times 10^{6}$ molec $\mathrm{cm}^{-3}$. Error bars indicate calibration uncertainty in $\mathrm{OH}$ exposure and $\pm 1 \sigma$ in $\mathrm{CCN} \kappa$ measurements.

hydrophilic particles having higher water solubility (Massoli et al., 2010).

\subsection{Flow tube design modifications}

Flow tube reactors can be used in a variety of ways to study aerosol chemistry, ranging from heterogeneous oxidation studies to CCN modification and SOA formation. Measurements presented in this paper suggest several design changes that are likely to modify aerosol flow tube performance. Replacing pyrex flow tube walls with a passivated conductive material (e.g. Silconert-coated stainless steel or high nickel-alloy steel) could increase particle transmission efficiency by minimizing electrostatic losses. Using a flow tube with a smaller diameter-to-length ratio yields narrower flow tube residence time distributions, which ensures that chemicals within the reactor experience a more uniform $\mathrm{OH}$ exposure for heterogeneous oxidation experiments. However, 
decreasing the diameter-to-length ratio increases the SA/V ratio and losses of wall-adhering gases and their secondary aerosol yields. For SOA formation experiments, decreasing the flow tube SA/V ratio and manipulating the flows so that the sampled air is not influenced by the walls are important modifications. As an example, the primary sample flow from the PAM subsamples gas and particles from the center of the tube (minimizing diffusional interactions with the walls) and a secondary peripheral flow removes air near the reactor walls.

\section{Summary}

This work evaluated two flow tube reactor designs (TPOT and PAM) in terms of gas and particle transmission efficiencies, residence time distributions (RTDs), and oxidized organic aerosols generated from gas- and particle-phase precursors ( $m$-xylene, $\alpha$-pinene, BES). The TPOT was developed for aerosol heterogeneous oxidation studies where uniform $\mathrm{OH}$ exposure is more important than minimizing wall losses. On the other hand, the PAM was developed with a separate flow to minimize wall interactions, as is important for SOA formation studies. First, transmission efficiency measurements for $\mathrm{CO}_{2}, \mathrm{SO}_{2}$, BES particles and $\mathrm{H}_{2} \mathrm{SO}_{4}$ were performed. Second, RTDs were measured for $\mathrm{CO}_{2}, \mathrm{SO}_{2}$ and BES particles. Third, $\mathrm{O} / \mathrm{C}$ ratio and $\mathrm{CCN}$ activity of $\mathrm{BES}$ particles exposed to $\mathrm{OH}$ radicals were characterized. Fourth, $\mathrm{O} / \mathrm{C}$ ratio and yield of $m$-xylene and $\alpha$-pinene SOA generated in the TPOT, the PAM and the Caltech chamber were compared. CCN activity of SOA generated in the flow tubes was also characterized. The intercomparison dataset is limited because the TPOT was available for this study for only a limited time ( 2 weeks). However, results are sufficient to draw conclusions about inherent advantages and disadvantages of the two designs.

The main difference between the flow tubes was the degree to which gases and aerosols interacted with reactor wall surfaces. The TPOT yielded narrower RTDs because of its larger length-to-diameter ratio. However, its transmission efficiency for gas-phase $\mathrm{SO}_{2}$ was lower than that for the PAM, either due to the increased accessibility of the walls within the reaction chamber or within the mixing chamber. SOA yields were also lower in the TPOT than in the PAM, which is consistent with enhanced wall loss of VOC oxidation products in the TPOT. Transmission efficiency for BES and $\mathrm{H}_{2} \mathrm{SO}_{4}$ particles was size-dependent and was similar for the two flow tube designs. The particle loss was sufficiently large that it needs to be accounted for in SOA formation studies.

Under similar oxidizing conditions, the $\mathrm{O} / \mathrm{C}$ ratio of BES particles processed in the flow tubes was similar. Hygroscopic properties (e.g., CCN activity) were similar at high oxidation conditions, but different at low oxidation conditions (Fig. 4). SOA O/C ratio and yields were strongly affected by reactor design and operating conditions. At comparable $\mathrm{OH}$ exposures, flow tube SOA was more oxidized than smog chamber SOA (Fig. 5), perhaps arising from enhanced oxidation occurring prior to particle nucleation. We are not certain of the reasons for this difference, but we note that smog chamber studies have been largely unable to match field observations of the degree of oxygenation of ambient aerosol, and so further studies in this regard are warranted. Also, the flow tube studies were conducted without a seed aerosol present, whereas the smog chamber results employed a seed, which likely plays an important role in promoting aerosol growth (Kroll et al., 2007). Flow tube SOA yields were consistently lower than smog chamber SOA yields (Figs. 6 and 7). The CCN activity of flow tubegenerated SOA particles was similar between the TPOT and PAM (Fig. 8).

Smog chambers require running long experiments and currently only access $\mathrm{OH}$ exposures $<1 \times 10^{11} \mathrm{molec} \mathrm{cm}^{-3} \mathrm{~s}$, or about 1 day of atmospheric aging. Wall effects are always present and are typically accounted for using size-dependent wall loss corrections. Flow tubes can characterize aerosols over atmospheric aging timescales of 1-10 days, but require high oxidant concentrations and also have wall effects that can influence measurements. The data presented illustrate the high degree of oxidation that can be achieved within such reactors. However, they also demonstrate that SOA yields from such reactors must be viewed with caution, given the important role that wall losses may be playing. A flow reactor that is operated with seed particles and/or a sheath flow to reduce wall interactions should be able to minimize wall effects and produce SOA yields that more closely represent true values. Overall, this work highlights the importance of flow tube and smog chamber comparisons to evaluate their utility as complementary tools for providing data inputs to climate and air quality models.

\section{Appendix A}

\section{Supporting information}

\section{A1 OH exposure calibrations}

$\mathrm{SO}_{2}$ was used to calculate the $\mathrm{OH}$ exposure in the flow tubes. First, $\mathrm{SO}_{2}$ was introduced with the lamps turned off until its initial concentration $\left(\mathrm{SO}_{2, \mathrm{i}}\right)$ remained constant at steadystate conditions. Then, the flow tube and ozone UV lamps were turned on and adjusted to a specific intensity. This condition was maintained until the final $\mathrm{SO}_{2}$ concentration $\left(\mathrm{SO}_{2, \mathrm{f}}\right)$ remained constant. Then, this procedure was repeated at several different conditions to obtain an $\mathrm{OH}$ exposure calibration. The $\mathrm{OH}$ exposure at each condition is calculated using Eq. (A1):

$$
\mathrm{OH} \text { exposure }=\frac{1}{k_{\mathrm{OH}, \mathrm{SO} 2}} \times-\ln \left(\frac{\mathrm{SO}_{2, \mathrm{f}}}{\mathrm{SO}_{2, \mathrm{i}}}\right)
$$




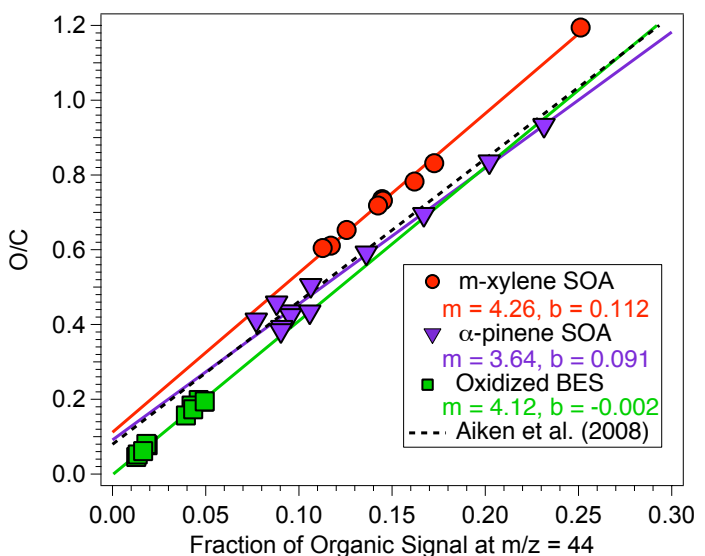

Fig. A1. Aerosol O/C ratio as a function of fraction of HR-ToFAMS organic signal at $m / z=44\left(f_{44}\right)$ for $m$-xylene SOA, $\alpha$-pinene SOA and oxidized BES particles generated in the TPOT and PAM. Aiken et al. (2008) O/C- $f_{44}$ parameterization is shown with a dashed line.

where $k_{\mathrm{OH}, \mathrm{SO} 2}=9 \times 10^{-13} \mathrm{~cm}^{3}$ molec $^{-1}$ is the bimolecular rate constant between $\mathrm{OH}$ and $\mathrm{SO}_{2}$ (Davis and Ravishankara, 1979). Equation (A1) is the result of integrating the differential rate equation for $\mathrm{SO}_{2}$ and assuming pseudo-first order kinetics. Using this type of calibration procedure has two advantages. First, any potential bias resulting from $\mathrm{SO}_{2}$ wall losses cancels out. Second, no assumptions about $\mathrm{SO}_{2}$ residence times need to be made, since the $\mathrm{OH}$ exposure (product of the $\mathrm{OH}$ concentration and average residence time) is determined directly from the initial and final $\mathrm{SO}_{2}$ concentrations.

\section{A2 O/C- $f_{44}$ parameterizations}

Figure A1 shows the aerosol O/C ratio determined from HRToF-AMS measurements plotted versus the fraction of organic signal at $m / z=44\left(f_{44}\right)$ for $m$-xylene SOA, $\alpha$-pinene SOA, and oxidized BES particles. The O/C ratio- $f_{44}$ parametermization from Aiken et al. (2008) is also shown. Calibrations from Fig. A1 were applied to several c-ToF-AMS measurements presented in Figs. 4 and 5 where corresponding HR-ToF-AMS measurements were unavailable. The Aiken et al. (2008) parameterization was applied to Caltech smog chamber data presented in Fig. 5.

\section{A3 CCN activation curves}

Figure A2 shows example $\mathrm{CCN}$ activation curves for oxidized BES particles, $m$-xylene SOA particles, and $\alpha$-pinene SOA particles, with the $\mathrm{CCN}$-activated fraction plotted as a function of water supersaturation. The critical supersaturation (50\% activation level) was determined by fitting a sigmoid curve to the $\mathrm{CCN}$ activation curves. To indicate the effect of particle chemistry on CCN activity, the markers in Fig. A2 are colored by their corresponding O/C ratios. As

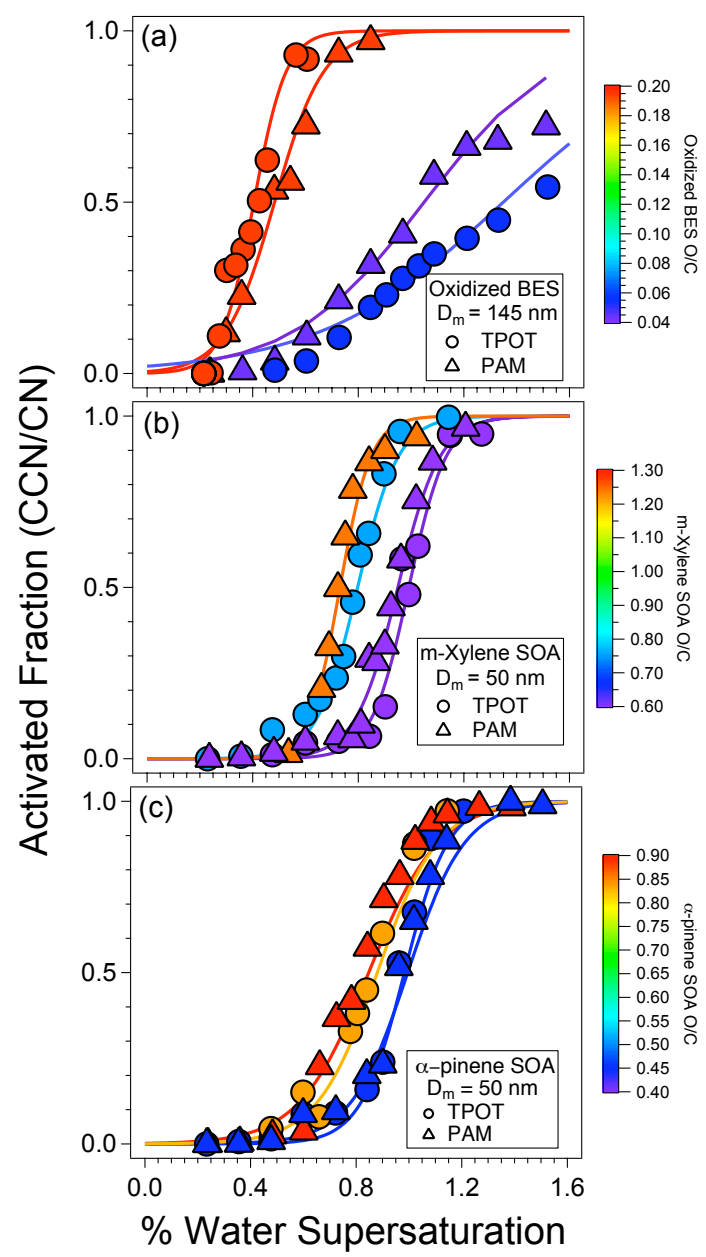

Fig. A2. CCN-activated particle fraction plotted as a function of water supersaturation for oxidized BES particles, $m$-xylene SOA particles and $\alpha$-pinene SOA particles generated in the TPOT and the PAM. Example CCN activation curves of (a) 145-nm oxidized BES particles, (b) 50-nm $m$-xylene SOA particles, and (c) 50-nm $\alpha$-pinene SOA particles are shown. Markers are colored by $\mathrm{O} / \mathrm{C}$ ratio.

the $\mathrm{O} / \mathrm{C}$ ratio was increased via increasing $\mathrm{OH}$ exposure, the critical supersaturation decreased (Fig. 8).

\section{A4 Taylor dispersion model for characterizing flow tube residence time distributions}

As discussed in Sect. 3.3, flow tube residence time distributions (RTDs) were compared with RTDs for ideal reactor models (Fig. 3). An ideal plug flow reactor (PFR) has no axial mixing and all fluid elements have the same residence time. An ideal laminar flow reactor also has no axial mixing, but is characterized by a wider RTD because of slower flow near the walls. The flow tube RTDs did not follow ideal reactor behaviour. Because the flow is laminar $(R e=15$ in TPOT and $R e=55$ in PAM), a model that describes axial dispersion 


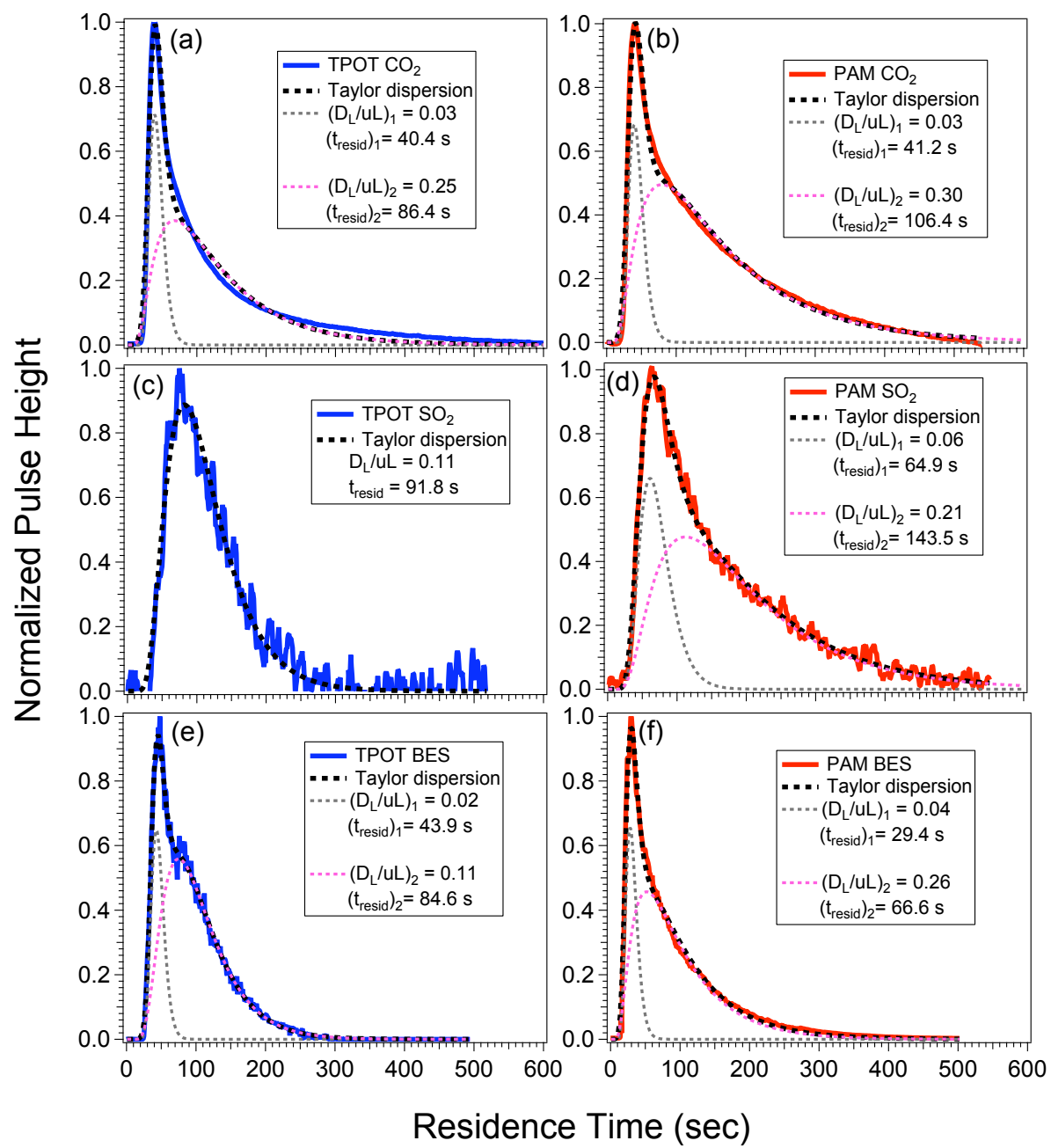

Fig. A3. Residence time distribution (RTD) measurements in the TPOT and PAM flow tubes. UV lamps were on during measurements. Measurements were fit to a Taylor dispersion model (dashed lines) with fit parameters shown in figure inserts. (a) $\mathrm{CO}_{2} \mathrm{RTD}$ in the TPOT (b) $\mathrm{CO}_{2} \mathrm{RTD}$ in the PAM (c) $\mathrm{SO}_{2} \mathrm{RTD}$ in the TPOT (d) $\mathrm{SO}_{2} \mathrm{RTD}$ in the PAM (e) BES RTD in the TPOT (f) BES RTD in the PAM.

in laminar flow (Taylor, 1953) was used to characterize the flow tube RTDs:

$D_{\mathrm{L}} \frac{\partial^{2} C}{\partial Z^{2}}-u \frac{\partial C}{\partial Z}=\frac{\partial C}{\partial t}$

where $D_{\mathrm{L}}$ is the axial diffusion coefficient $\left(\mathrm{cm}^{2} \mathrm{~s}^{-1}\right), u$ is the flow velocity $\left(\mathrm{cm} \mathrm{s}^{-1}\right)$, and $C$ is the tracer concentration $\left(\right.$ molec $\mathrm{cm}^{-3}$ ) at time $t(\mathrm{~s})$ and axial distance $Z(\mathrm{~cm})$. At $Z=L$ (reactor length), the reactor response to a pulsed tracer input is given by Eq. (A3) (Levenspiel and Smith, 1957; Hill Jr., 1977):

$C(t)=\frac{C_{\mathrm{o}}}{2 \sqrt{\pi\left(\frac{D_{\mathrm{L}}}{u L}\right)\left(t / t_{\text {resid }}\right)}} e^{-\frac{\left[\left(1-\left(t / t_{\text {resid }}\right)\right)\right]^{2}}{\left(\frac{4 D_{\mathrm{L}}}{u L\left(t / t_{\text {resid }}\right)}\right.}}$

where $t_{\text {resid }}$ is the average residence time of the tracer, assuming constant fluid density. The $D_{\mathrm{L}} / u L$ quantity is proportional to the amount of dispersion ("effective dispersion coefficient").

Equation (A3) was fit to the TPOT $\mathrm{SO}_{2}$ RTD as shown in Fig. A3c. $\mathrm{SO}_{2}$-wall interactions in the TPOT create a wide $\mathrm{SO}_{2}$ RTD that is well-described by Eq. (A3). Other RTDs $\left(\mathrm{CO}_{2}, \mathrm{BES}, \mathrm{PAM} \mathrm{SO} \mathrm{SO}_{2}\right)$ were characterized by a sharp initial pulse followed by a long tail (Fig. A3a,b and e,f), and Eq. (A3) did not provide a good fit. The fit to a Taylor dispersion model was improved by assuming that two dispersion timescales govern the flow (i.e., there are two distinct flow regimes). This assumption is likely to more closely model the complexity of the flow patterns: one direct flow path through the flow tube systems and a secondary flow path that undergoes recirculation within the flow tube. A modified Taylor dispersion model was derived to characterize both flow components (first component with minor dispersion, second component with significant dispersion) and is shown in Eq. (A4): 


$$
\begin{aligned}
& C(t)=\frac{C_{\mathrm{o}}}{2 \sqrt{\pi\left(\frac{D_{\mathrm{L}}}{u L}\right)_{1}\left(t / t_{\text {resid }}\right)_{1}}} e^{-\frac{\left[\left(1-\left(t / t_{\text {resid }}\right)_{1}\right)\right]^{2}}{\left(\frac{D_{\mathrm{L}}}{u L}\right)_{1}\left(t / t_{\mathrm{resid}}\right)_{1}}} \\
&+\frac{C_{\mathrm{o}}}{2 \sqrt{\pi\left(\frac{D_{\mathrm{L}}}{u L}\right)_{2}\left(t / t_{\mathrm{resid}}\right)_{2}}} e^{-\frac{\left[\left(1-\left(t / t_{\text {resid }}\right)_{2}\right]^{2}\right.}{\left(\frac{4 D_{\mathrm{L}}}{u L}\right)_{2}\left(t / \text { resid }_{2}\right.}}
\end{aligned}
$$

Equation (A4) was fit to $\mathrm{CO}_{2}$, BES, and PAM $\mathrm{SO}_{2}$ RTDs (Fig. A3a,b and d-f).

The flow model employed here provides a self-consistent, qualitative interpretation of the observed experimental results, including characterizing both components of the flow tube RTDs. The $\mathrm{CO}_{2}$ RTD was narrower in the TPOT than in the PAM, especially for the secondary (in time) flow component, as indicated by the smaller effective dispersion coefficients (0.03 and 0.25 versus 0.03 and 0.30$)$. The BES RTDs were also characterized by smaller dispersion coefficients in the TPOT $(0.02$ and 0.11$)$ than in the PAM (0.04 and 0.26). These results suggest that less dispersion causes narrower RTDs in the TPOT than in the PAM, as expected, based on the flow tube geometries that were employed. However, our application of this model is not rigorous as our specific cases do not appear to meet the strict criteria for Taylor dispersion (radial diffusion $\gg$ axial residence time). While several factors may help relax the criteria in our cases, including two apparently well-defined flow regimes (limiting effective radial dimensions) and the well-mixed conditions of the trace gas or particles, this model does not provide a complete physical interpretation of the measured RTDs.

\section{A5 $\mathrm{H}_{2} \mathrm{SO}_{4}$ transmission efficiency calculations}

The measured sulfuric acid aerosol mass is given by Eq. (A5):

$\mathrm{H}_{2} \mathrm{SO}_{4, \text { meas }}=x_{\mathrm{H}_{2} \mathrm{SO}_{4}} \times V_{\mathrm{H}_{2} \mathrm{SO}_{4} \cdot \mathrm{H}_{2} \mathrm{O}} \times \rho_{\mathrm{H}_{2} \mathrm{SO}_{4} \cdot \mathrm{H}_{2} \mathrm{O}}$

where $x_{\mathrm{H}_{2} \mathrm{SO}_{4}}$ is the mass fraction of $\mathrm{H}_{2} \mathrm{SO}_{4}$ in solu-

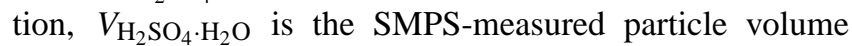
$\left(\mathrm{nm}^{3} \mathrm{~cm}^{-3}\right)$, and $\rho_{\mathrm{H}_{2} \mathrm{SO}_{4} \cdot \mathrm{H}_{2} \mathrm{O}}\left(\mathrm{g} \mathrm{cm}^{-3}\right)$ is the density of the $\mathrm{H}_{2} \mathrm{SO}_{4}-\mathrm{H}_{2} \mathrm{O}$ solution following water uptake by $\mathrm{H}_{2} \mathrm{SO}_{4}$.

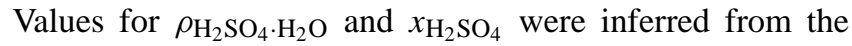
relative humidity of the aerosol flow (Seinfeld and Pandis, 2006) sampled by the SMPS. The dry yield of $\mathrm{H}_{2} \mathrm{SO}_{4}$ from $\mathrm{OH}$ oxidation of $\mathrm{SO}_{2}$ is $3.95 \mu \mathrm{g} \mathrm{m}^{-3}$ per ppb $\mathrm{SO}_{2}$ reacted. Therefore, the $\mathrm{H}_{2} \mathrm{SO}_{4}$ transmission efficiency is given by Eq. (A5):

$\mathrm{H}_{2} \mathrm{SO}_{4}$ transmission efficiency $=\frac{\mathrm{H}_{2} \mathrm{SO}_{4, \text { meas }}}{3.95 \times \Delta \mathrm{SO}_{2}}$

where $\Delta \mathrm{SO}_{2}$ is the amount of $\mathrm{SO}_{2}$ reacted (ppb) after turning on the flow tube UV lamps.
Acknowledgements. We thank Diana van Duin (Pennsylvania State University) for preparing compressed $\alpha$-pinene and $m$-xylene gas canisters used in this work, Eben Cross (MIT), Lino Gonzalez (ARI), and Charles Kolb (ARI) for useful feedback and discussion. We also thank the reviewers for useful feedback on the discussions paper. This research was supported by the Office of Science (BER), Department of Energy (Atmospheric Science Program) grant No. DE-FG02-05ER63995 and the Atmospheric Chemistry Program of the National Science Foundation grants No. ATM-0525355 and ATM-0854916 to Boston College and Aerodyne Research, Inc. Support for the TPOT studies came from NSERC and Environment Canada.

Edited by: D. Heard

\section{References}

Aiken, A. C., DeCarlo, P. F., and Jimenez, J. L.: Elemental analysis of organic species with electron ionization high-resolution mass spectrometry, Anal. Chem., 79(21), 8350-8358, 2007.

Aiken, A. C., Decarlo, P. F., Kroll, J. H., Worsnop, D. R., Huffman, J. A., Docherty, K. S., Ulbrich, I. M., Mohr, C., Kimmel, J. R., Sueper, D., Sun, Y., Zhang, Q., Trimborn, A., Northway, M., Ziemann, P. J., Canagaratna, M. R., Onasch, T. B., Alfarra, M. R., Prevot, A. S. H., Dommen, J., Duplissy, J., Metzger, A., Baltensperger, U., and Jimenez, J. L.: O/C and OM/OC ratios of primary, secondary, and ambient organic aerosols with high-resolution time-of-flight aerosol mass spectrometry, Environ. Sci. Technol., 42, 4478-4485, doi:10.1021/es703009q, 2008.

Atkinson, R.: Kinetics and mechanisms of the gas-phase reactions of the hydroxyl radical with organic compounds under atmospheric conditions, Chem. Rev., 86(1), 69-201, 1986.

Bertram, A. K., Ivanov, A. V., Hunter, M., Molina, L. T., and Molina, M. J.: The reaction probability of $\mathrm{OH}$ on organic surfaces of tropospheric interest, J. Phys. Chem. A, 105, 9415-9421, 2001.

Cooper, P. L. and Abbatt, J. P. D.: Heterogeneous interactions of $\mathrm{OH}$ and $\mathrm{HO}_{2}$ radicals with surfaces characteristic of atmospheric particulate matter, J. Phys. Chem., 100, 2249-2254, 1996.

Davis, D. D., Ravishankara, A. R., and Fischer, S.: $\mathrm{SO}_{2}$ Oxidation via the Hydroxyl Radical: Atmospheric Fate of $\mathrm{HSO}_{\mathrm{x}}$ Radicals, Geophys. Res. Lett., 6, 113-116, 1979.

de Gouw, J. A. and Lovejoy, E. R.: Reactive uptake of ozone by liquid organic compounds, Geophys. Res. Lett., 25, 931-934, 1998.

DeCarlo, P. F., Kimmel, J. R., Trimborn, A., Northway, M. J., Jayne, J. T., Aiken, A. C., Gonin, M., Fuhrer, K., Horvath, T., Docherty, K. S., Worsnop, D. R., and Jimenez, J. L.: Fielddeployable, high-resolution, time-of-flight aerosol mass spectrometer, Anal. Chem., 78, 8281-8289, doi:10.1021/ac061249n, 2006.

Donahue, N. M., Robinson, A. L., Stanier, C. O., and Pandis, S. N.: Coupled partitioning, dilution, and chemical aging of semivolatile organics, Environ. Sci. Technol., 40, 2635-2643, 2006.

Drewnick, F., Hings, S. S., DeCarlo, P., Jayne, J. T., Gonin, M., Fuhrer, K., Weimer, S., Jimenez, J. L., Demerjian, K. L., Borrmann, S., and Worsnop, D. R.: A new time-of-flight aerosol mass spectrometer (ToF-AMS) - instrument description 
and first field deployment, Aerosol Sci. Tech., 39, 637-658, doi:10.1080/02786820500182040, 2005.

George, I. J., Vlasenko, A., Slowik, J. G., Broekhuizen, K., and Abbatt, J. P. D.: Heterogeneous oxidation of saturated organic aerosols by hydroxyl radicals: uptake kinetics, condensed-phase products, and particle size change, Atmos. Chem. Phys., 7, 4187-4201, doi:10.5194/acp-7-4187-2007, 2007.

George, I. J., Chang, R. Y. W., Danov, V., Vlasenko, A., and Abbatt, J. P. D.: Modification of cloud condensation nucleus activity of organic aerosols by hydroxyl radical heterogeneous oxidation, Atmos. Environ., 43, 5038-5045, doi:10.1016/j.atmosenv.2009.06.043, 2009.

Hallquist, M., Wenger, J. C., Baltensperger, U., Rudich, Y., Simpson, D., Claeys, M., Dommen, J., Donahue, N. M., George, C., Goldstein, A. H., Hamilton, J. F., Herrmann, H., Hoffmann, T., Iinuma, Y., Jang, M., Jenkin, M. E., Jimenez, J. L., Kiendler-Scharr, A., Maenhaut, W., McFiggans, G., Mentel, Th. F., Monod, A., Prévôt, A. S. H., Seinfeld, J. H., Surratt, J. D., Szmigielski, R., and Wildt, J.: The formation, properties and impact of secondary organic aerosol: current and emerging issues, Atmos. Chem. Phys., 9, 5155-5236, doi:10.5194/acp-95155-2009, 2009.

Hanson, D. R. and Lovejoy, E. R.: The reaction of $\mathrm{ClONO}_{2}$ with submicrometer sulfuric-acid aerosol, Science, 267, 1326-1328, 1995.

Heald, C. L., Kroll, J. H., Jimenez, J. L., Docherty, K. S., DeCarlo, P. F., Aiken, A. C., Chen, Q., Martin, S. T., Farmer, D. K., and Artaxo, P.: A simplified description of the evolution of organic aerosol composition in the atmosphere, Geophys. Res. Lett., 37, L08803, doi:10.1029/2010GL042737, 2010.

Hearn, J. D. and Smith, G. D.: A mixed-phase relative rates technique for measuring aerosol reaction kinetics, Geophys. Res. Lett., 33, L17805, doi:10.1029/2006GL026963, 2006.

Hill Jr., C. G.: An Introduction to Chemical Engineering Kinetics and Reactor Design, John Wiley and Sons, New York, 1977.

Hinds, W. C.: Aerosol Technology: Properties, Behavior, and Measurement of Airborne Particles, Wiley-Interscience, New York, 1999.

Joshi, S. B., Dodge, M. C., and Bufalini, J. J.: Reactivities of selected organic-compounds and contamination effects, Atmos. Environ., 16, 1301-1310, 1982.

Kang, E., Root, M. J., Toohey, D. W., and Brune, W. H.: Introducing the concept of Potential Aerosol Mass (PAM), Atmos. Chem. Phys., 7, 5727-5744, doi:10.5194/acp-7-5727-2007, 2007.

Katrib, Y., Bishos, G., Buseck, P. R., Davidovits, P., Jayne, J. T., Mochida, M., Wise, M. E., Worsnop, D. R., and Martin, S. T.: Ozonolysis of mixed oleic acid/stearic acid particles: reaction kinetics and chemical morphology, J. Phys. Chem. A, 109, 1091010919, 2005.

Kroll, J. H. and Seinfeld, J. H.: Chemistry of secondary organic aerosol: formation and evolution of low-volatility organics in the atmosphere, Atmos. Environ., 42, 3593-3624, doi:10.1016/j.atmosenv.2008.01.003, 2008.

Kroll, J. H., Chan, A. W. H., Ng, N. L., Flagan, R. C., and Seinfeld, J. H.: Reactions of semivolatile organics and their effects on secondary organic aerosol formation, Environ. Sci. Technol., 41(10), 3545-3550, 2007.
Kroll, J. H., Smith, J. D., Che, D. L., Kessler, S. H., Worsnop, D. R., and Wilson, K. R.: Measurement of fragmentation and functionalization pathways in the heterogeneous oxidation of oxidized organic aerosol, Phys. Chem. Chem. Phys., 11, 8005-8014, doi:10.1039/b905289e, 2009.

Lambe, A. T., Miracolo, M. M., Hennigan, C. J., Robinson, A. L., and Donahue, N. M.: Effective rate constants and uptake coefficients for the reactions of organic molecular markers ( $n$-alkanes, hopanes and steranes) in motor oil and diesel primary organic aerosols with hydroxyl radicals, Environ. Sci. Technol., 43, 23, 8794-8800, 2009.

Levenspiel, O. and Smith, W. K.: Notes on the diffusion-type model for the longitudinal mixing of fluids in flow, Chem. Eng. Sci., 6, 227-233, 1957.

Lonneman, W. A., Bufalini, J. J., Kuntz, R. L., and Meeks, S. A.: Contamination from fluorocarbon films, Environ. Sci. Technol., 15, 99-103, 1981.

Mao, J., Ren, X., Brune, W. H., Olson, J. R., Crawford, J. H., Fried, A., Huey, L. G., Cohen, R. C., Heikes, B., Singh, H. B., Blake, D. R., Sachse, G. W., Diskin, G. S., Hall, S. R., and Shetter, R. E.: Airborne measurement of OH reactivity during INTEX-B, Atmos. Chem. Phys., 9, 163-173, doi:10.5194/acp-9-163-2009, 2009.

Massoli, P., Lambe, A. T., Ahern, A. T., Williams, L. R., Ehn, M., Mikkilä, J., Canagaratna, M. R., Brune, W. H., Onasch, T. B., Jayne, J. T., Petäjä, T., Kulmala, M., Laaksonen, A., Kolb, C. E., Davidovits, P., and Worsnop, D. R.: Relationship between aerosol oxidation level and hygroscopic properties of laboratory generated secondary organic aerosol (SOA) particles, Geophys. Res. Lett., 37, L24801, doi:10.1029/2010GL045258, 2010.

Matsunaga, A. and Ziemann, P. J.: Gas-wall partitioning of organic compounds in a teflon film chamber and potential effects on reaction product and aerosol yield measurements, Aerosol Sci. Tech., 44(10), 881-892, 2010.

McMurry, P. H. and Grosjean, D.: Gas and aerosol wall losses in teflon film smog chambers, Environ. Sci. Technol., 19, 1176$1182,1985$.

McMurry, P. H. and Rader, D. J.: Aerosol wall losses in electrically charged chambers, Aerosol Sci. Tech., 4, 249-268, 1985.

McNeill, V. F., Yatavelli, R. L. N., Thornton, J. A., Stipe, C. B., and Landgrebe, O.: Heterogeneous $\mathrm{OH}$ oxidation of palmitic acid in single component and internally mixed aerosol particles: vaporization and the role of particle phase, Atmos. Chem. Phys., 8, 5465-5476, doi:10.5194/acp-8-5465-2008, 2008.

Mentel, T. F., Bleilebens, D., and Wahner, A.: A study of nighttime nitrogen oxide oxidation in a large reaction chamber - the fate of $\mathrm{NO}_{2}, \mathrm{~N}_{2} \mathrm{O}_{5}, \mathrm{HNO}_{3}$, and $\mathrm{NO}_{3}^{-}$at different humidities, Atmos. Environ., 30, 4007-4020, 1996.

Morris, J. W., Davidovits, P., Jayne, J. T., Jimenez, J. L., Shi, Q., Kolb, C. E., Worsnop, D. R., Barney, W. S., and Cass, G.: Kinetics of submicron oleic acid aerosols with ozone: a novel aerosol mass spectrometric technique, Geophys. Res. Lett., 29, 1357, doi:10.1029/2002GL014692, 2002.

Ng, N. L., Chhabra, P. S., Chan, A. W. H., Surratt, J. D., Kroll, J. H., Kwan, A. J., McCabe, D. C., Wennberg, P. O., Sorooshian, A., Murphy, S. M., Dalleska, N. F., Flagan, R. C., and Seinfeld, J. H.: Effect of $\mathrm{NO}_{\mathrm{x}}$ level on secondary organic aerosol (SOA) formation from the photooxidation of terpenes, Atmos. Chem. Phys., 7, 5159-5174, doi:10.5194/acp-7-5159-2007, 2007a. 
Ng, N. L., Kroll, J. H., Chan, A. W. H., Chhabra, P. S., Flagan, R. C., and Seinfeld, J. H.: Secondary organic aerosol formation from $m$-xylene, toluene, and benzene, Atmos. Chem. Phys., 7, 3909-3922, doi:10.5194/acp-7-3909-2007, 2007b.

Odum, J. R., Hoffman, T., Bowman, F., Collins, D., Flagan, R. C., and Seinfeld, J. H.: Gas/particle partitioning and secondary organic aerosol yields, Environ. Sci. Technol., 30, 2580-2585, 1996.

Petters, M. D., Prenni, A. J., Kreidenweis, S. M., DeMott, P. J., Matsunaga, A., Lim, Y. B., and Ziemann, P. J.: Chemical aging and the hydrophobic-to-hydrophilic conversion of carbonaceous aerosol, Geophys. Res. Lett., 33, L24806, doi:10.1029/2006g1027249, 2006.

Petters, M. D. and Kreidenweis, S. M.: A single parameter representation of hygroscopic growth and cloud condensation nucleus activity, Atmos. Chem. Phys., 7, 1961-1971, doi:10.5194/acp-71961-2007, 2007.

Pierce, J. R., Engelhart, G. J., Hildebrandt, L., Weitkamp, E. A., Pathak, R. K., Donahue, N. M., Robinson, A. L., Adams, P. J., and Pandis, S. N.: Constraining particle evolution from wall losses, coagulation, and condensation-evaporation in smogchamber experiments: optimal estimation based on size distribution measurements, Aerosol Sci. Tech., 42, 1001-1015, doi:10.1080/02786820802389251, 2008.

Presto, A. A., Hartz, K. E. H., and Donahue, N. M.: Secondary organic aerosol production from terpene ozonolysis, 1. Effect of UV radiation, Environ. Sci. Technol., 39, 7036-7045, doi:10.1021/es050174m, 2005.
Qi, L., Nakao, S., Tang, P., and Cocker III, D. R.: Temperature effect on physical and chemical properties of secondary organic aerosol from $m$-xylene photooxidation, Atmos. Chem. Phys., 10, 3847-3854, doi:10.5194/acp-10-3847-2010, 2010.

Robbins, R. C. and Cadle, R. D.: Kinetics of the reaction between gaseous ammonia and sulfuric acid droplets in an aerosol, J. Phys. Chem., 62, 469-471, 1958.

Roberts, G. C. and Nenes, A.: A continuous-flow streamwise thermal-gradient $\mathrm{CCN}$ chamber for atmospheric measurements, Aerosol Sci. Tech., 39, 206-221, 2005.

Rudich, Y., Donahue, N. M., and Mentel, T. F.: Aging of organic aerosol: bridging the gap between laboratory and field studies, Annu. Rev. Phys. Chem., 58, 321-352, 2007.

Seinfeld, J. H. and Pandis, S. N.: Atmospheric Chemistry and Physics: From Air Pollution to Climate Change, John Wiley and Sons, Inc., New York, 2006.

Smith, J. D., Kroll, J. H., Cappa, C. D., Che, D. L., Liu, C. L., Ahmed, M., Leone, S. R., Worsnop, D. R., and Wilson, K. R.: The heterogeneous reaction of hydroxyl radicals with submicron squalane particles: a model system for understanding the oxidative aging of ambient aerosols, Atmos. Chem. Phys., 9, 3209-3222, doi:10.5194/acp-9-3209-2009, 2009.

Stanier, C. O., Pathak, R. K., and Pandis, S. N.: Measurements of the volatility of aerosols from alpha-pinene ozonolysis, Environ. Sci. Technol., 41, 2756-2763, doi:10.1021/es0519280, 2007.

Taylor, G. I.: Dispersion of soluble matter in solvent flowing slowly through a tube, P. Roy. Soc. Lond. A, 219, 186-203, 1953.

Turpin, B. J., Saxena, P., and Andrews, E.: Measuring and simulating particulate organics in the atmosphere: problems and prospects, Atmos. Environ., 34, 2983-3013, 2000. 